\author{
Universidade de São Paulo \\ Faculdade de Economia, Administração e Contabilidade de \\ Ribeirão Preto \\ Departamento de Economia \\ Programa de Pós-graduação em Economia
}

\title{
Risco cambial num sistema de equações com choques correlacionados
}

Fernanda Isadora Mundim Gonçalves

Orientador: Prof. Dr. Alex Luiz Ferreira

\section{RIBEIRÃO PRETO}


Prof. Dr. Marco Antonio Zago

Reitor da Universidade de São Paulo

Prof. Dr. Dante Pinheiro Martinelli

Diretor da Faculdade de Economia, Administração e Contabilidade de Ribeirão Preto

Prof. Dr. Renato Leite Marcondes

Chefe do Departamento de Economia

Prof. Dr. Cláudio Lucinda

Coordenador do Programa de Pós-graduação em Economia 


\section{FERNANDA ISADORA MUNDIM GONÇALVES}

Risco cambial num sistema de equações com choques correlacionados

Dissertação apresentada ao Programa de Pós-Graduação em Economia - Área: Economia Aplicada da Faculdade de Economia, Administração e Contabilidade de Ribeirão Preto da Universidade de São Paulo, para obtenção do título de Mestre em Ciências. Versão Corrigida. A original encontra-se disponível na FEA-RP/USP.

Orientador: Prof. Dr. Alex Luiz Ferreira

\section{RIBEIRÃO PRETO}

2016 
Autorizo a reprodução e divulgação total ou parcial deste trabalho, por qualquer meio convencional ou eletrônico, para fins de estudo e pesquisa, desde que citada a fonte.

Gonçalves, Fernanda Isadora Mundim

Risco cambial num sistema de equações com choques correlacionados/ Fernanda Isadora Mundim Gonçalves; Orientador: Prof. Dr. Alex Luiz Ferreira

RIBEIRÃO PRETO, 2016- 63 p. : il.

Dissertação (Mestrado) - Universidade de São Paulo, 2016.

1. Risco 2. Taxa de câmbio 3. SUR I. Orientador: Prof. Dr. Alex Luiz Ferreira II. Universidade de São Paulo - USP - Ribeirão Preto. III. Faculdade de Economia Administração e Contabilidade. IV. Risco cambial num sistema de equações com choques correlacionados 


\section{Agradecimentos}

Ao chegar à reta final de mais uma etapa da vida, é inevitável relembrar todas as decisões que motivaram os primeiros passos. Lembro-me de meus agradecimentos da graduação, em que disse "Mudanças, sejam bem-vindas!". De fato, a decisão pelo mestrado representou uma grande mudança: a pós graduação não foi apenas um salto discreto em meu aprendizado e conhecimento, mas também a porta de entrada para minha independência, ao sair de casa, de BH, de Minas Gerais. A escolha pela USP$\mathrm{RP}$, não planejada inicialmente, porém muito bem recebida, trouxe-me uma nova vida, acompanhada pelo conhecido turbilhão de emoções que acompanha as mudanças...

A solidão de morar sozinha, o susto com a profundidade em que todas as matérias eram abordadas, o medo de não dar conta de tudo, o cansaço da vida tripla BH-RP-SP, todas as dificuldades e desafios do primeiro ano do mestrado (e por que não também do segundo?) jamais teriam sido superadas se não fosse por vocês, meus dois amores: Mamãe e Papai, que sempre me apoiaram em todas as minhas decisões, que sempre desejaram meu melhor e sempre estiveram ao meu lado. Obrigada por todas as vezes em que ficaram horas no telefone comigo, ajudando a espantar a solidão, pelo cantinho que montaram para mim com tanto amor e carinho, por todas as visitas, por todas as vezes que limparam minha casa enquanto eu estudava e por fazerem as voltas à $\mathrm{BH}$ sempre valerem a pena.

Muito da escolha por Ribeirão esteve relacionada a você: Du, meu amor e companheiro, sem você eu nunca teria conseguido. Obrigada por acreditar na minha capacidade e por sempre dar um jeitinho de me assegurar que eu daria conta. Obrigada pela compreensão nos momentos em que não podíamos nos ver por causa das provas, por todas as maravilhosas lembranças de nossos passeios por Ribeirão e por me receber em sua vida cotidiana em SP. Acima de tudo, obrigada pela motivação nessa reta final, quando a rotina de trabalhar e dissertar já me sufocava, e você estava ali, sempre pronto a me incentivar: "Vamo que vamo!"

Não poderia deixar de agradecer a todos aqueles que acompanharam quase diariamente toda essa história: amigos do mestrado, nossa turma corajosa e perseverante, nossa família em RP. Por todos os estudos, estresses, discussões, desesperos e parcerias, muito obrigada! Alguns, arrisco citar nominalmente: Ju, amiga para toda a vida, parceira de estudos e caminhadas, de banco, de desabafos, de comemorações com vinho! Obrigada por tudo. Kazita, companheira de saídas em Ribeirão, de discussões cabeça, você foi essencial nesse percurso, obrigada por sua animação. Victory, ponderada, obrigada por me mostrar que SP também produz pessoas sensacionais. Gabi, sempre me acalmando com sua experiência, obrigada pelas inúmeras risadas com seus casos, por me levar ao médico quando precisei, por me receber tão bem! Igor, obrigada por fazer com que Minas 
não parecesse tão longe! Rodrigo, sempre gentil, obrigada por todas as vezes em que me ajudou. Um muito obrigada especial também para as meninas do Ásanas Pilates, responsáveis por momentos divertidos (embora árduos, não posso deixar de dizer) que me ajudaram a manter a sanidade.

Agradeço também a todos os professores da FEA-RP pelos ensinamentos e por nos estimularem a seguir em frente. Em especial, agradeço ao meu orientador, Alex, que permitiu a existência deste trabalho. Obrigada pela parceria, sempre. Um obrigada também à Professora Roseli, que em um pequeno espaço de tempo, conseguiu me mostrar a beleza da docência, uma porta que ainda se mantém entreaberta.

Não poderia me esquecer de vocês, amigos e família de BH e do mundo! Deixo aqui um pedido de desculpas por todas as vezes em que me ausentei, que sumi para me dedicar aos estudos e aos meus objetivos. Obrigada por me compreenderem e por estarem sempre presentes, apesar de tudo.

Nesse momento, tem-se o fim de uma fase. Uma fase difícil, porém muito recompensadora. Uma fase que começou ao me graduar economista pela UFMG, e acaba com o título de Mestre pela USP-RP. A caminhada como economista, no entanto, continua, e a busca pelo conhecimento não termina. Espero que, com tudo que aprendi nessa maravilhosa oportunidade que tive, eu consiga contribuir para a sociedade, para um mundo melhor. E que venham novas mudanças e novos desafios! 


\section{Resumo}

GONÇALVES, F. I. M. Risco cambial num sistema de equações com choques correlacionados. 2016. Dissertação (Mestrado) - Faculdade de Economia, Administração e Contabilidade de Ribeirão Preto, Universidade de São Paulo, Ribeirão Preto, 2016.

Este trabalho apresenta uma abordagem inovadora para a modelagem do risco cambial. Ao invés de utilizar regressões de MQO "equação por equação", explora-se a correlação contemporânea e estrutural entre os choques de preferência num sistema de equações de precificação de ativos. Estima-se um modelo via SUR em uma amostra de excessos de retorno de países entre 1999Q1 e 2014Q2, utilizando-se novos fatores de risco associados ao PIB das diferentes economias. O modelo empírico é derivado de preferências que são consistentes com um problema de economia aberta, em contraste com a abordagem habitual que utiliza o crescimento do consumo de bens duráveis e não-duráveis como fatores de risco. A estratégia econométrica escolhida leva a uma melhora significativa da precisão das quantidades de risco (betas) estimadas. A relação positiva entre taxas de juros e quantidades de risco, contudo, não é corroborada para todos os betas.

Palavras-chave: juros. câmbio. risco. 


\begin{abstract}
GONÇALVES, F. I. M. Currency risk in a system of equations with correlated shocks. 2016. Dissertation (Masters) - Faculdade de Economia, Administração e Contabilidade de Ribeirão Preto, Universidade de São Paulo, Ribeirão Preto, 2016.

This thesis presents an innovative approach for modeling currency risk. Instead of using equation by equation OLS, we explore the structural contemporaneous correlation between preference shocks across a system of asset pricing equations. SUR regressions as well as new risk factors lead to a marked improvement in efficiency for the estimation of the quantities of risk (betas) in a sample of country excess returns from 1999Q1 to 2014Q2. However, the monotonic relation between interest rates and quantities of risk is not statistically significant for all betas. Our model is derived from preferences that are consistent to an open economy problem, in contrast to the typical approach of using durable and non-durable consumption growth as risk factors.
\end{abstract}

Key-words: interest rates. exchange rates. risk. 
Sumário

Sumário . . . . . . . . . . . . . . . . . . 8

Lista de ilustrações . . . . . . . . . . . . . . . . . 9

Lista de tabelas . . . . . . . . . . . . . . . 10

Introdução . . . . . . . . . . . . . . . . . 11

Teoria . . . . . . . . . . . . . . . . . . . . 12

$2.1 \quad$ Revisão Bibliográfica . . . . . . . . . . . . . . . . . . 12

2.2 Modelo Teórico . . . . . . . . . . . . . . . . . . . 18

2.3 Equilíbrio: PIB ao invés de consumo . . . . . . . . . . . . . 21

3 Choques correlacionados: metodologia . . . . . . . . . . . 22

$3.1 \quad$ SUR: Estratégia Empírica . . . . . . . . . . . . . . . . 22

$3.2 \quad$ Dados . . . . . . . . . . . . . . . . 27

3.2.1 Construção dos Dados . . . . . . . . . . . . . . . . 27

3.2.2 Estatísticas Descritivas . . . . . . . . . . . . . . . . . . . 30

$3.3 \quad$ Consumo X PIB . . . . . . . . . . . . . . . . 34

$4 \quad$ Resultados . . . . . . . . . . . . . . . 35

4.1 Resultados preliminares: estimação MQO . . . . . . . . . . . . . 36

$4.2 \quad$ Estimações SUR . . . . . . . . . . . . . . . . . 39

$4.2 .1 \quad$ SUR Recursivo . . . . . . . . . . . . . . . . . . . . 44

$4.3 \quad$ Classificações de Risco . . . . . . . . . . . . . . . . . . . 49

$4.4 \quad$ Outros testes de robustez . . . . . . . . . . . . . . . . . . 53

5 Considerações Finais . . . . . . . . . . . . . . 58

Referências .........................661

ANEXO ......................... 62 


\section{Lista de ilustrações}

Figura 1 - Excesso de retorno Brasil X Ciclo NBER . . . . . . . . . . . . . . . 32

Figura 2 - Excesso de retorno Japão X Ciclo NBER . . . . . . . . . . . . . . . . 33

Figura 3 - Excesso de retorno Suíça X Ciclo NBER . . . . . . . . . . . . . 33

Figura 4 - Excesso de retorno Turquia X Ciclo NBER . . . . . . . . . . . . 33

Figura 5 - Consumo Doméstico / PIB ao longo do tempo: EUA . . . . . . . . . 35

Figura 6 - Estimação MQO com 2 fatores: $\hat{\beta}_{1}^{j} \ldots \ldots \ldots$. . . . . . . . . 37

Figura 7 - Estimação MQO com 2 fatores: $\hat{\beta}_{2}^{j} \ldots \ldots \ldots$. . . . . . . . . 37

Figura 8 - Estimação MQO com 1 fator: $\beta_{1}^{j} \ldots \ldots \ldots$. . . . . . . . 38

Figura 9 - Estimação MQO com 1 fator: $\hat{\beta}_{2}^{j} \ldots \ldots$. . . . . . . . . . . . 39

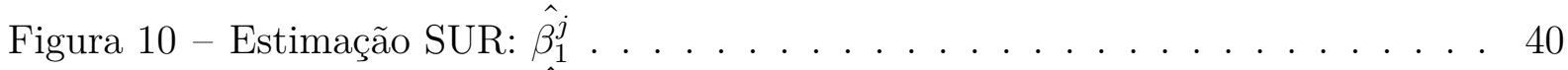

Figura 11 - Estimação SUR: $\hat{\beta}_{2}^{j} \ldots \ldots \ldots$. . . . . . . . . . . . . 40

Figura 12 - Estimação SUR Treasury Bills: $\hat{\beta}_{1}^{j} \ldots \ldots \ldots$. . . . . . . . . . . 44

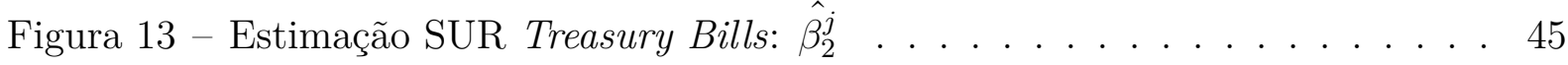

Figura 14 - Série da Quantidade de Risco $\beta_{1 t}^{\hat{K} O}$ - Coréia do Sul . . . . . . . . . . 46

Figura 15 - Série da Quantidade de Risco $\beta_{1 t}^{\hat{T} U}$ - Turquia . . . . . . . . . . . . 47

Figura 16 - Série da Quantidade de Risco $\beta_{1 t}^{I T}$ - Israel . . . . . . . . . . . . . . . 47

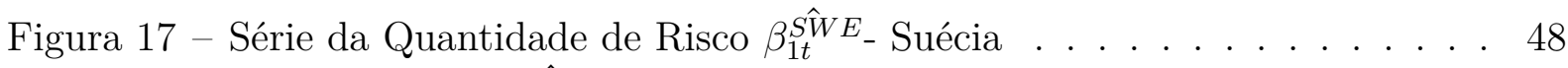

Figura 18 - Estimação SUR: $\hat{\beta}_{1}^{j}$ ordenados por excesso de retorno médio . . . . . . 50

Figura 19 - Estimação SUR: $\hat{\beta}_{2}^{j}$ ordenados por excesso de retorno médio . . . . . . 50

Figura 20 - Estimação SUR: $\hat{\beta}_{1}^{j}$ ordenados por depreciação média . . . . . . . . . . 51

Figura 21 - Estimação SUR: $\hat{\beta}_{2}^{j}$ ordenados por depreciação média . . . . . . . . . . 52

Figura 22 - Estimação SUR: $\beta_{1}^{j, G E} \ldots \ldots \ldots \ldots \ldots \ldots$

Figura 23 - Estimação SUR: $\beta_{1}^{j \hat{U} K} \ldots \ldots \ldots \ldots \ldots \ldots$ 


\section{Lista de tabelas}

Tabela 1 - Crescimento trimestral do PIB (em \%) - estatísticas descritivas . . . . 31

Tabela 2 - Excessos de Retorno (em \%) - estatísticas descritivas . . . . . . . . . 32

Tabela 3 - Regressão dos Betas sobre Médias de Taxa de Juros e Posições no Rank 41

Tabela 4 - Percentagem de Betas Significantes . . . . . . . . . . . . . 43

Tabela 5 - Testes de Zeros e Spreads . . . . . . . . . . . . . . . 43

Tabela 6 - Regressão dos Betas sobre Excesso de Retorno Médio e Depreciação Média . . . . . . . . . . . . . . . . . 52

Tabela 7 - Percentagem de Betas Significantes: Modelo Alemanha . . . . . . . . . 57

Tabela 8 - Percentagem de Betas Significantes: Modelo Reino Unido . . . . . . . 57

Tabela 9 - Regressão dos Betas sobre Médias de Taxa de Juros e Posições no Rank: Modelo Alemanha . . . . . . . . . . . . . . . . . . . . 62

Tabela 10 - Testes de Zeros e Spreads: Modelo Alemanha . . . . . . . . . . . . . . 62

Tabela 11 - Regressão dos Betas sobre Médias de Taxa de Juros e Posições no Rank: Modelo Reino Unido . . . . . . . . . . . . . . . . . . . . . 63

Tabela 12 - Testes de Zeros e Spreads: Modelo Reino Unido . . . . . . . . . . . . . 63 



\section{Introdução}

Entre as atividades especulativas existentes no mercado de câmbio, tem-se a estratégia de carry trade, na qual um agente toma recursos emprestados em moedas com baixas taxas de juros, para reaplicá-los em outra moeda cujos títulos ofereçam uma remuneração mais elevada. Essa estratégia envolve riscos pois, mesmo que no momento da aplicação o diferencial de juros seja elevado, o que determinará o retorno obtido via carry trade é a taxa de câmbio no momento em que se resgata o dinheiro aplicado, conforme se depreende da PDTJ (Paridade descoberta da taxa de juros). Afinal, a moeda do país com taxa de juros elevada pode depreciar ao ponto de compensar o diferencial de juros inicial, de modo a proporcionar ganhos negativos nessa operação. O risco cambial embutido nessa estratégia especulativa é o objeto de estudo desta dissertação.

Conforme apontado em Ferreira (2014), a literatura recente sobre os determinantes do risco cambial (Yogo (2006), Lustig e Verdelhan (2007), Burnside (2011) e Lustig e Verdelhan (2011)) apresenta resultados bastante controversos. Lustig e Verdelhan (2007) aplicam a estrutura do modelo de precificação de ativos baseado em consumo de Yogo (2006) para o mercado de títulos internacionais e encontram como resultado que a quantidade de risco de um portfólio de excessos de retorno aumenta com a sua média de taxa de juros. Burnside (2011), por sua vez, critica Lustig e Verdelhan (2007) (e a réplica em Lustig e Verdelhan (2011)) ao mostrar que não é possível rejeitar, do ponto de vista estatístico, que as quantidades de risco estimada são iguais a zero, não se podendo afirmar, portanto, que há relação monotônica entre risco e taxa de juros.

Essa controvérsia ilustra a dificuldade em se encontrar parâmetros estatisticamente significativos em modelos de precificação de ativos: a principal razão é que a variância dos excessos de retorno tende a ser muito mais elevada que a variância dos fatores de risco utilizados na estimação. Ferreira e Moore (2015) avançam nessa questão, uma vez que desenvolvem um modelo teórico que utiliza o consumo de bens domésticos e estrangeiros como fatores de risco, estes mais voláteis que o consumo de duráveis e não-duráveis, mais comumente usados. De fato, os autores encontram uma melhora na precisão dos betas de consumo estimados. 
O presente estudo contribui para a literatura na medida em que complementa e avança sobre o trabalho de Ferreira e Moore (2015) ao derivar, a partir de seu modelo de precificação de ativos com fatores de consumo de economias abertas, uma estrutura empírica que permite a sua estimação via SUR - Seemingly Unrelated Regressions. Ao invés de estimar o modelo equação por equação via MQO, explora-se a correlação estrutural entre os choques de preferência de cada equação. Desenvolve-se essa estratégia de estimação a partir da hipótese de equilíbrio em Lucas (1982), substituindo-se os fatores de consumo pela taxa de crescimento do PIB dos países. Outras contribuições deste trabalho são a estimação recursiva que analisa o comportamento da quantidade de risco dos diferentes países ao longo do tempo e a discussão acerca de classificações de risco alternativas.

Os resultados da estimação SUR para uma amostra de excessos de retorno de 22 economias, entre 1999Q1 e 2014Q2, mostram que, de fato, ocorre um ganho de precisão dos coeficientes estimados: há um aumento de cerca de $50 \%$ da quantidade de betas estatisticamente significativos, ao se comparar com a literatura. No que diz respeito à relação positiva entre quantidades de risco e taxas de juros, esta é observada apenas para os coeficientes associados ao PIB doméstico. Tais coeficientes se relacionam positivamente não somente com a média de taxa de juros, mas também com a taxa de depreciação média durante períodos de recessão norte-americana.

O restante do trabalho se divide da seguinte maneira: detalha-se a controvérsia empírica da literatura no capítulo 2, bem como a teoria e o modelo utilizados; a metodologia SUR e a base de dados são descritas no capítulo 3; no capítulo 4, apresenta-se os resultados encontrados. Por fim, no capítulo 5, tem-se algumas considerações finais.

\section{Teoria}

\subsection{Revisão Bibliográfica}

Ao se precificar ativos, deve-se levar em conta o risco embutido em cada um deles. A relação entre preços, retornos e riscos pode ser explicada a partir das decisões de um 
investidor sobre o quanto poupar, o quanto consumir, e em quais ativos investir. A teoria econômica sugere que a perda de utilidade marginal ao se consumir um pouco menos hoje e investir o que não foi consumido deve se igualar ao ganho esperado de utilidade marginal de se utilizar o dinheiro investido e o seu retorno para consumir futuramente descontados intertemporalmente e pela incerteza.

A partir dessa condição, pode-se explicar a relação entre o retorno (taxa de juros) dos ativos e a utilidade marginal no ciclo econômico: os ativos que pagam menos quando o consumo é baixo (e a utilidade marginal elevada) são considerados mais arriscados e são vendidos por um menor preço, refletindo retornos maiores, que compensem pelo risco incorrido. Ativos que pagam relativamente mais quando o consumo é baixo (e a utilidade marginal alta), por sua vez, funcionam como um seguro: possuem retornos reduzidos ou negativos na maior parte do tempo, mas pagam demasiadamente bem quando ocorre um sinistro (recessão econômica com baixos níveis de consumo, por exemplo, no caso macroeconômico). Assim, "marginal utility is the appropriate measure of risk for an investor who cares about consumption"(YOGO, 2006, p. 544).

O risco embutido nos ativos, portanto, está associado à covariância entre seus retornos e o consumo ou a utilidade marginal:

For a given expected payoff of an asset, an asset that does badly in states like a recession, in which the investor feels poor and is consuming little, is less desirable than an asset that does badly in states of nature like a boom when the investor feels wealthy and is consuming a great deal. The former assets will sell for lower prices; their prices will reflect a discount for their riskiness, and this riskiness depends on a co-variance. (COCHRANE, 2005, p. 13)

As ideias apresentadas acima originam-se no modelo CCAPM (Consumption Capital Asset Pricing Model). Nesse modelo, o prêmio de risco esperado de um ativo em relação ao ativo sem risco é proporcional à covariância de seu retorno com a taxa de crescimento do consumo do agente. Ou seja, a incerteza é mapeada em risco pela utilidade que os retornos dos ativos proporcionam ao agente no ciclo econômico. No Capital Asset Pricing Model (CAPM) original, por sua vez, o excesso de retorno esperado de um ativo depende não de sua covariância com os fatores de consumo, mas da sua covariância com 
um fator de mercado. (COCHRANE, 2005)

É importante explicar um conceito importante que advém de tais modelos, que será repetido constantemente nesse trabalho: os betas dos fatores de risco. No modelo CCAPM, o coeficiente de uma regressão do retorno de um ativo sobre a taxa de crescimento do consumo é conhecido como beta de consumo. O modelo CAPM original, por sua vez, estabelece uma regressão de excessos de retorno sobre um índice do retorno do portfólio de mercado, provendo, assim, coeficientes chamados de betas de mercado. Temse, dessa maneira, que a principal previsão que os modelos CAPM e CCAPM fazem é que os prêmios de risco que os ativos oferecem são proporcionais aos seus betas - de mercado e de consumo, respectivamente.(ROMER, 2010)

O modelo desenvolvido em Yogo (2006), diferentemente do modelo CCAPM, desagrega o consumo entre bens duráveis, não duráveis e o fator de mercado. O consumo de bens duráveis é mais variável que o consumo de bens não-duráveis no ciclo, contribuindo assim para a modelagem econométrica dos excessos de retorno, uma vez que estes são, por natureza, muito mais voláteis.

A estratégica empírica deste autor para testar a relevância do consumo de duráveis para a determinação do risco no mercado de ações é a estimação de um modelo linear de fatores, baseado num modelo teórico de otimização da utilidade de um indivíduo representativo. Este maximiza sua utilidade - função de utilidade intertemporal recursiva de Epstein e Zin (1989)-, que depende do consumo de bens duráveis e não-duráveis, sujeito à sua restrição orçamentária e de riqueza. A ideia é a seguinte:

In equilibrium, differences in expected returns across assets must reflect differences in the quantity of risk across assets, measured by the covariance of returns with nondurable and durable consumption growth.(YOGO, 2006, p. 555)

Espera-se, então, que o excesso de retorno esperado seja maior se os betas referentes

1 O modelo linear é bastante geral, abrangendo os seguintes modelos: modelo de utilidade intertemporal recursiva de Epstein-Zin (utilidade aditivamente separável do coeficiente de aversão relativa ao risco e da elasticidade de substituição intertemporal), modelo de utilidade não-separável (em que a elasticidade intertemporal do consumo é o inverso do coeficiente de aversão relativa ao risco), CAPM e CCAPM. 
ao consumo de duráveis e não-duráveis forem maiores:

(...) the expected return on an asset is high when the co- variance of its returns with nondurable consumption growth is high. Similarly, the expected return is high when the covariance of its returns with durable consumption growth is high. (YOGO, 2006, p. 564)

Segundo Yogo (2006), a inclusão do consumo de bens duráveis no modelo CCAPM explica bem a variação no tempo e em corte transversal do excesso de retorno das ações. Logo, representa um avanço em relação aos modelos tradicionais de precificação de ativos até então descritos.

Os trabalhos de Lustig e Verdelhan (2007), Burnside (2011) e Lustig e Verdelhan (2011) utilizam a base teórica de Yogo (2006), aplicando suas ideias para o mercado de títulos domésticos e estrangeiros. Lustig e Verdelhan (2007) constroem oito portfólios de excesso de retornos de diferentes moedas, baseando-se nas taxas de juros dos países. Tais portfólios são construídos com pesos simétricos e sempre são rebalanceados, de modo que o primeiro contenha os países com menores taxas de juros e o último englobe as moedas cujos países possuam taxas de juros mais elevadas.

Para estimar um modelo de fatores linear, parte-se das mesmas condições de primeira ordem obtidas no modelo de Yogo (2006). Lustig e Verdelhan (2007) utilizam, na estimação, o procedimento em dois estágios de Fama e MacBeth (1973). No primeiro estágio da estimação, para cada portfólio j, estima-se uma regressão em séries temporais do retorno de cada moeda sobre uma constante e sobre os fatores de consumo e de mercado, a fim de se obter os betas de consumo. No segundo estágio, estima-se uma regressão em corte transversal, em que as médias dos excessos de retorno de cada portfólio são regredidas sobre os betas obtidos, a fim de se estimar o preço dos fatores de risco ${ }^{2}$. Para tanto, Lustig e Verdelhan (2007) usam dados anuais sobre os retornos de Treasury Bills dos EUA e de países estrangeiros e dados de consumo norte-americanos.

Segundo os autores supracitados, os resultados encontrados ${ }^{3}$ indicam que os modelos baseados no consumo explicam bem a variação em corte transversal dos excessos

2 "The factor price measures the expected excess return on an asset that has a consumption growth beta of one."(LUSTIG; VERDELHAN, 2007, p. 97)

3 Não se reporta, aqui, os resultados referentes ao segundo estágio da estimação, pois as conclusões 
de retorno de títulos estrangeiros em relação aos títulos norte-americanos. Corrobora-se, ainda, a ideia de que moedas de países com taxas de juros médias mais elevadas são mais arriscadas, uma vez que seus betas de consumo são maiores.

Em relação à significância estatística de tais parâmetros, contudo, somente dois betas de consumo estimados individualmente foram estatisticamente diferentes de zero no trabalho de Lustig e Verdelhan (2007). Quando estimados condicionalmente a outros fatores, nenhum deles foi estatisticamente significativo. Ainda assim, os autores concluem que "The average annual returns are almost monotonically increasing in the interest rate differential". (LUSTIG; VERDELHAN, 2007, p. 93)

Burnside (2011) apresenta argumentos contrários às evidências encontradas por Lustig e Verdelhan (2007). De acordo com o primeiro, a ausência de significância dos betas encontrados torna errônea a conclusão de Lustig e Verdelhan (2007) de que os títulos de países com taxas de juros maiores são mais arriscados.

Respondendo às críticas feitas por Burnside (2011), Lustig e Verdelhan (2011) argumentam que os betas estimados individualmente deveriam ser usados para testar para o spread entre eles. Para eles, a significância da diferença entre os betas é mais importante do que a significância individual destes. Os autores realizam, assim, testes sobre as diferenças, encontrando que estas são significativamente diferentes de zero, ao contrário do que é reportado nos testes de spread realizados em Burnside (2011). (FERREIRA; MOORE, 2015)

Como teste de robustez, Lustig e Verdelhan (2011) repetem os exercícios realizados em Lustig e Verdelhan (2007) para uma amostra que engloba o período da recente crise dos EUA. Durante crises, como já mencionado, a taxa de crescimento da utilidade marginal do consumo é alta, enquanto a taxa de crescimento do consumo é baixa. Logo, moedas mais arriscadas depreciariam em momentos de recessão. Os autores estimam o modelo somente com o fator de consumo de bens duráveis e encontram betas de consumo significativos apenas para dois portfólios.

depreendidas deste fogem ao escopo do presente trabalho, que foca na significância dos betas de consumo estimados. 
A partir dos artigos mencionados, observa-se que a significância dos betas de consumo estimados é um tema controverso nessa literatura. (FERREIRA, 2014; FERREIRA; MOORE, 2015) A dificuldade em se obter estimadores mais precisos está, em parte, associada à grande volatilidade dos excessos de retorno em relação à variação observada nos fatores de consumo. Uma vez que a variância dos betas estimados é proporcional à variância dos resíduos mas inversamente relacionada à variância das variáveis explicativas, uma pequena variabilidade do consumo - oriunda de um possível comportamento de suavização - aumentaria a variância dos estimadores.

Visando contribuir para uma melhor estimação dos betas de consumo na modelagem dos excessos de retorno de diferentes moedas, Ferreira e Moore (2015) desenvolvem um modelo teórico com base em fatores de consumo de bens domésticos e importados, específicos de economias abertas. A justificativa teórica para a inclusão desses novos determinantes reside na microfundamentação das razões pelas quais se adquire títulos estrangeiros: poupança precaucionária em moeda estrangeira, suavização do consumo de importados etc. Além disso, o consumo de bens importados possui maior variância em relação aos fatores até então utilizados, o que contribui para um menor desvio padrão dos parâmetros estimados.

Os autores utilizam dados trimestrais referentes a países que representam cerca de 99\% do volume das transações em moeda estrangeira no mundo ${ }^{4}$, entre $1973 \mathrm{~T} 2$ e $2012 \mathrm{~T} 3$. Diferentemente dos modelos até então citados, Ferreira e Moore (2015) optaram pela frequência trimestral dos dados, devido à maior compatibilidade com o ciclo de negócios. Ademais, a análise foi feita com países ao invés de portfólios.

Os resultados obtidos revelam maior precisão na estimativa dos betas de consumo, sendo os spreads entre estes significativos. Além disso, encontra-se betas maiores para economias com taxas de juros médias mais elevadas. Como ressaltado pelos autores, a escolha de amostras de países, períodos e frequências adequadas resultou em maior eficiência na estimação dos parâmetros. (FERREIRA; MOORE, 2015).

O presente trabalho, portanto, insere-se na fronteira dessa literatura, na medida

$4 \quad$ Segundo Relatório do BIS (2013). 
em que investiga um modelo econométrico alternativo ao de Ferreira e Moore (2015) que possibilite melhorar ainda mais a precisão dos betas estimados. Tal melhora é possível a partir do procedimento de estimação SUR (Seemingly Unrelated Regressions), conforme se descreve no capítulo 3.

\subsection{Modelo Teórico}

Esta seção se baseia no modelo de Ferreira e Moore (2015), o qual utiliza o crescimento do consumo de bens domésticos e importados como fatores de risco, e não o consumo de bens duráveis e não-duráveis, como levantado na revisão bibliográfica.

Sejam duas economias: H (Home) e F (Foreign), populadas por um agente representativo. O agente doméstico escolhe sua trajetória de alocação de consumo ótima ao decidir o quanto comprar de bens domésticos e importados, bem como quanto possuir de títulos domésticos e estrangeiros. Assim, este escolhe consumir $C_{t}$ unidades do bem doméstico e $C_{t}^{*}$ unidades do bem importado. No início de cada período, uma dotação em

moeda doméstica, $\tilde{Y}_{t}$, e uma dotação estocástica em moeda estrangeira, $\tilde{Y}_{t}^{*}$, são recebidas.

O problema do agente representativo doméstico é, assim, maximizar sua utlidade

$$
U_{t}=E_{t} \sum_{s=t}^{\infty} \delta^{s-t} u\left(C_{s}, C_{s}^{*}\right)
$$

sujeita à restrição de alocação de riqueza entre consumo e poupança,

$$
W_{t}=P_{t} C_{t}+P_{t}^{*} C_{t}^{*} S_{t}+B_{t} P_{t}^{B}+B_{t}^{*} S_{t} P_{t}^{B^{*}}
$$

à equação de movimento da riqueza,

$$
W_{t+1}=B_{t}+B_{t}^{*} S_{t+1}+P_{t+1} \tilde{Y}_{t+1}+P_{t+1}^{*} \tilde{Y}_{t+1}^{*} S_{t+1}
$$

a uma riqueza inicial e a uma condição de transversalidade, com $s=t, t-1, \ldots, \infty$.

$B_{t}$ e $B_{t}^{*}$ são as quantidades de títulos domésticos e estrangeiros (variáveis de estado); $E_{t}$ é a esperança condicional em todas as informações disponíveis até o tempo t; $\delta$ 
é o fator de desconto intertemporal subjetivo ao agente. $W_{t}$, por sua vez, é a riqueza no início de cada período t; $P_{t}$ é o nível de preços da cesta de consumo doméstica e $S_{t}$ a taxa de câmbio nominal, definida como o preço da moeda estrangeira em moeda doméstica. Os asteriscos se referem às variáveis do país estrangeiro.

A resolução do problema de maximização leva ao seguinte resultado:

$$
E_{t}\left(M_{t+1} R_{t+1}^{e}\right)=0
$$

em que $M_{t+1}$ é definido, por hipótese, como o fator de desconto estocástico (FDE) ${ }^{5}$ e é dado por:

$$
M_{t+1} \equiv \beta\left(\frac{u_{1}\left(C_{t+1}, C_{t+1}^{*}\right)}{u_{1}\left(C_{t}, C_{t}^{*}\right)}\right)
$$

$R_{t+1}^{e}$, por sua vez, é o excesso de retorno esperado entre os títulos dos países $\mathrm{H}$ e F e é definido como: $R_{t+1}^{e} \equiv\left[\left(R_{t+1}^{*} \frac{Q_{t+1}}{Q_{t}}-R_{t+1}\right)\right]^{6}$.

A equação 4 é a tradicional equação de apreçamento fundamental na literatura de finanças (ver Cochrane (2005)) e mostra que as expectativas dos excessos de retorno teóricos descontados pelo FDE são iguais a zero. Em outras palavras, o agente representativo não desperdiça oportunidades de lucro esperado descontado.

Em relação às preferências do indivíduo representativo, considera-se a utilidade de cada período como uma CRRA (Constant Relative Risk Aversion):

$$
u\left(C_{t}, C_{t}^{*}\right)=\frac{v\left(C_{t}, C_{t}^{*}\right)^{1-\gamma}}{1-\gamma}
$$

em que $\gamma$ é o coeficiente de aversão ao risco relativo e $v\left(C_{t}, C_{t}^{*}\right)=\left[(1-\alpha) C_{t}^{\rho}+\right.$ $\left.\alpha C_{t}^{* \rho}\right]^{1 / \rho}$ é a utilidade dentro de cada período, com $\alpha \in(0,1)$ e $\rho \leq 1$.

5 De acordo com a literatura de precificação de ativos baseada no consumo.

6 Tem-se $Q_{t} \equiv \frac{P_{t}^{*} S_{t}}{P_{t}}$ igual à taxa de câmbio real, $1+r_{t+1} \equiv \frac{1+i_{t}}{1+\pi_{t+1}}$ (em que $r$ é taxa de juros real e $\pi$ a taxa de inflação, com $\left.1+\pi_{t+1} \equiv \frac{P_{t+1}}{P_{t}}\right)$ e $R_{t+1} \equiv\left(1+r_{t+1}\right)$ igual ao retorno real de um título. 
Para se obter a forma linear do modelo, utiliza-se uma aproximação de primeira ordem do logaritmo do FDE, $\ln M_{t+1}$ na vizinhança de sua média incondicional $\left(E\left(\ln M_{t+1}\right)\right)^{7}$ O modelo linear é dado por:

$$
E\left(R_{t}^{j, e}\right)=b_{1} \operatorname{Cov}\left(\Delta c_{t}, R_{t}^{j, e}\right)+b_{2} \operatorname{Cov}\left(\Delta c_{t}^{*}, R_{t}^{j, e}\right)
$$

em que $b_{1} \equiv \gamma+\alpha(1-\gamma-\rho)$ e $b_{2} \equiv-\alpha(1-\gamma-\rho)$.

As controvérsias empíricas da literatura, contudo, dizem respeito aos betas de consumo do modelo. Para se chegar à representação beta do modelo linear, seguindo Ferreira e Moore (2015), considere um FDE linear em $f_{t} \equiv\left[f_{1 t} f_{2 t}\right]^{\top}$, que denota o vetor transposto dos fatores de risco. Pode-se obter, assim, uma equação correspondente à equação (6), porém reescrita levando-se em conta a nova notação:

$$
E\left(R_{t}^{j, e}\right)=b^{\top} \Sigma_{f j}
$$

em que $\Sigma_{f j} \equiv E\left[\left(f_{t}-\mu_{f}\right) R_{t}^{j, e}\right], \mu_{f} \equiv E\left(f_{t}\right)$ e o vetor transposto $b \equiv\left[\begin{array}{ll}b_{1} & b_{2}\end{array}\right]^{\top}$ é o vetor de parâmetros que multiplica as covariâncias do consumo no modelo linear $(6)^{8}$. A equação (7) mostra que o excesso de retorno pode ser dividido entre o preço do fator, b, e a quantidade de risco, $\Sigma_{f j}$.

Definindo $\Sigma_{f f} \equiv E\left[\left(f_{t}-\mu_{t}\right)\left(f_{t}-\mu_{t}\right)^{\top}\right]$ e $\beta^{j} \equiv \Sigma_{f f}^{-1} \Sigma_{f j}$ tem-se que $\Sigma_{f j}=\Sigma_{f f} \beta^{j}$. Logo,

$$
E\left(R_{t}^{j, e}\right)=b^{\top} \Sigma_{f f} \beta^{j}
$$

Ao se assumir $\lambda^{\top} \equiv b^{\top} \Sigma_{f f}$, a equação (8) se torna

$$
E\left(R_{t}^{j, e}\right)=\lambda^{\top} \beta^{j}
$$


O preço do risco é dado por $\lambda$ e a quantidade de risco dada pelos $\beta^{j}$. Estes, por sua vez, podem ser interpretados como os coeficientes de uma regressão linear múltipla de $R_{t}^{j . e}$ sobre $f_{t}-\mu_{t}$ :

$$
R_{t}^{j, e}=\beta_{j}\left(f_{t}-\mu_{f}\right)+u_{t}^{j}
$$

Dessa forma, tem-se a equação empírica

$$
R_{t}^{j, e}=\beta_{0}+\beta_{1} \Delta c_{t}+\beta_{2} \Delta c_{t}^{*}+u_{t}^{j}
$$

\subsection{Equilíbrio: PIB ao invés de consumo}

Diferentemente do que foi realizado em Yogo (2006), Lustig e Verdelhan (2007), Burnside (2011) e Lustig e Verdelhan (2011), o foco da estratégia de estimação aqui utilizada está somente na estimação dos betas de consumo $\beta^{j}$, e não nos preços dos fatores de risco $\lambda$. Para tanto, a ideia é estimar uma regressão dos excessos de retorno $R_{t}^{j, e}$ sobre os fatores de consumo, conforme apresentado na equação 11.

Dada a controvérsia empírica da literatura discutida na seção 2.1, propõe-se uma estratégia de estimação simultânea - via SUR (Seemingly Unrelated Regressions) - que tem o potencial de trazer ganhos de eficiência à estimação por mínimos quadrados ordinários (MQO), provendo melhorias em relação à significância dos parâmetros estimados. Para garantir a consistência entre a estratégia empírica e a teoria apresentada, assume-se uma hipótese teórica adicional, proveniente do modelo de equilíbrio geral de Lucas (1982). Este modelo assume a hipótese de existência de um equilíbrio simétrico com mercados completos e total compartilhamento de riscos, em uma economia de dotação com dois países. O modelo teórico de Ferreira e Moore (2015) apresentado na seção anterior, por sua vez, segue a estrutura do modelo de economia aberta de Lucas (1982).

Considere um planejador central que busca maximizar

$$
\phi_{H} u\left(C_{t}, C_{t}^{*}\right)+\phi_{F} u^{F}\left(C_{t}^{F}, C_{t}^{F *}\right)
$$


sujeito às condições de disponibilidade de recursos $C_{t}+C_{t}^{F *}=Y_{t}$ e $C_{t}^{F}+C_{t}^{*}=Y_{t}^{*}$. Os parâmetros $\phi_{H}$ e $\phi_{F}$ são os pesos associados a cada país, H e F. $u^{F}$ e $u$ representam as funções de utilidade do país $\mathrm{F}$ e $\mathrm{H}$, respectivamente. $C_{t}^{F *}$ é o quanto o agente do país $\mathrm{F}$ consome dos bens do país H. A condição de primeira ordem do problema do planejador central, na dimensão do consumo de bens do país $\mathrm{H}, \mathrm{e}^{9}$ :

$$
\phi_{H} u_{1}(.)=\phi_{F} u_{1}^{F}(.)
$$

Assumindo-se pesos idênticos para os dois países (equilíbrio simétrico), as utilidades marginais representadas acima serão iguais, implicando que, no ponto ótimo de equilíbrio e sob a ótica do agente H, o consumo dos bens do país H (consumo de bens domésticos) e o consumo dos bens do país F (consumo de bens importados) serão iguais à metade do PIB (Produto Interno Bruto) de cada uma dessas economias:

$$
\begin{aligned}
& C_{t}=C_{t}^{F *}=Y_{t}\left(2^{-1}\right), \\
& C_{t}^{*}=C_{t}^{F}=Y_{t}^{*}\left(2^{-1}\right) .
\end{aligned}
$$

Essa solução teórica do modelo, no caso de duas economias simétricas, sugere a possibilidade de se usar dados de PIB ao invés de dados de consumo na estimação da equação empírica 11 oriunda do modelo linear. Tal estratégia é seguida ao longo deste trabalho e será detalhada no capítulo seguinte, bem como a sua contribuição para os testes usualmente apresentados na literatura.

\section{Choques correlacionados: metodologia}

\subsection{SUR: Estratégia Empírica}

Assumindo-se o modelo de dois países análogo ao de Lucas (1982), descrito no capítulo 2, os dados de consumo de bens domésticos e importados podem ser substituídos $9 \quad$ Para mais detalhes, ver Lucas (1982). 
pelo PIB dos diferentes países (representado pelas variáveis $Y_{t}$ e $Y_{t}^{*}$ ). No caso, a taxa de crescimento do PIB norte-americano será utilizada como proxy para o PIB doméstico; e a taxa de crescimento do PIB do país j como proxy para o PIB do país estrangeiro. A equação a ser estimada para cada país j, assim, é:

$$
R_{t}^{j, e}=\beta_{0}^{j}+\beta_{1}^{j} \Delta y_{t}^{E U A}+\beta_{2}^{j} \Delta y_{t}^{j}+u_{t}^{j} \quad j=1,2, \ldots, J
$$

em que $R_{t}^{j, e}$ é o excesso de retorno de títulos do país j em relação aos títulos norteamericanos, $\Delta y_{t}^{E U A}$ é a taxa de crescimento do PIB da economia doméstica (EUA) e $\Delta y_{t}^{j}$ representa o crescimento da economia estrangeira j. $\beta_{1}^{j}$ e $\beta_{2}^{j}$ são os betas dos fatores de risco, $\beta_{0}^{j}$ é uma constante e $u_{t}^{j}$ é o termo de erro de cada equação j.

Uma vez que a estimação via SUR pressupõe um conjunto de instrumentos comuns a todas as equações estimadas, a utilização da variável PIB garante a consistência entre a parte teórica e a implementação empírica. Afinal, com a substituição dos fatores de consumo pelo PIB, a variável $\Delta y_{t}^{E U A}$ estará presente em todas as equações do modelo, conforme se depreende da equação 14 .

Outra vantagem associada à utilização do PIB dos países no lugar dos fatores de consumo está associada à maior variação esperada da renda em relação à variação do consumo, uma vez que o mesmo é suavizado em equilíbrio. Do ponto de vista empírico, a variância dos estimadores tende a diminuir, uma vez que esta é inversamente relacionada à variância das variáveis explicativas.

O modelo $\mathrm{SUR}^{10}$ representado pela equação 14 pode ser visto, matricialmente, como:

$$
\mathbf{R}_{\mathbf{t}} \equiv\left[\begin{array}{c}
\mathbf{R}_{\mathbf{t}}^{\mathbf{1}, \mathbf{e}} \\
\mathbf{R}_{\mathbf{t}}^{\mathbf{2}, \mathbf{e}} \\
\vdots \\
\mathbf{R}_{\mathbf{t}}^{\mathbf{J}, \mathbf{e}}
\end{array}\right]=\left[\begin{array}{cccc}
\mathbf{X}_{\mathbf{t}}^{\mathbf{1}} & \mathbf{0} & \ldots & \mathbf{0} \\
\mathbf{0} & \mathbf{X}_{\mathbf{t}}^{\mathbf{2}} & \ldots & \mathbf{0} \\
\vdots & \vdots & \ldots & \vdots \\
\mathbf{0} & \mathbf{0} & \ldots & \mathbf{X}_{\mathbf{t}}^{\mathbf{J}}
\end{array}\right]\left[\begin{array}{c}
\beta^{\mathbf{1}} \\
\beta^{\mathbf{2}} \\
\vdots \\
\beta^{\mathbf{J}}
\end{array}\right]+\left[\begin{array}{c}
\mathbf{u}_{\mathbf{t}}^{\mathbf{1}} \\
\mathbf{u}_{\mathbf{t}}^{\mathbf{2}} \\
\vdots \\
\mathbf{u}_{\mathbf{t}}^{\mathbf{J}}
\end{array}\right]=\mathbf{X}_{\mathbf{t}} \beta+\mathbf{u}_{\mathbf{t}}
$$

10 A especificação do modelo SUR feita no presente trabalho segue a apresentação realizada em Greene (2003). 
em que $\beta^{\mathbf{j}} \equiv\left(\beta_{0 j}, \beta_{1 j}, \beta_{2 j}\right)^{\top}$ são os vetores transpostos dos betas estimados para cada equação j, e

$$
\mathbf{R}_{\mathbf{t}}^{\mathbf{j}, \mathbf{e}} \equiv\left(\begin{array}{c}
R_{1}^{j, e} \\
R_{2}^{j, e} \\
\vdots \\
R_{T}^{j, e}
\end{array}\right), \mathbf{X}_{\mathbf{t}}^{\mathbf{j}} \equiv\left(\begin{array}{ccc}
1 & \Delta y_{1}^{E U A} & \Delta y_{1}^{j} \\
1 & \Delta y_{2}^{E U A} & \Delta y_{2}^{j} \\
\vdots & \vdots & \vdots \\
1 & \Delta y_{T}^{E U A} & \Delta y_{T}^{j}
\end{array}\right), \mathbf{u}_{\mathbf{t}}^{\mathbf{j}} \equiv\left(\begin{array}{c}
u_{j 1} \\
u_{j 2} \\
\vdots \\
u_{j T}
\end{array}\right)
$$

Compactamente,

$$
\underset{(J T \times 1)}{\mathbf{R}_{\mathbf{t}}}=\underset{(J T \times J)(J \times 1)}{\mathbf{X}_{\mathbf{t}}}+\underset{(J T \times 1)}{\beta}
$$

A principal hipótese do modelo é:

$$
u_{j t}=\epsilon_{j t}+\xi_{t}
$$

em que $\epsilon_{j t}$ são choques idiossincráticos de cada país, independentes entre si e independentes de $\xi_{t}$, o qual pode ser definido, por exemplo, como um choque de preferências que impacta o agente norte-americano representativo de nosso modelo teórico. Assim, tem-se que:

$$
\begin{array}{ll}
E\left(u_{t j} u_{t i} \mid \mathbf{X}_{\mathbf{t}}\right)=\sigma_{j i} \quad \text { se } j \neq i \text { e } \sigma_{j j} \text { caso contrário, } \\
E\left(u_{t j} u_{s j} \mid \mathbf{X}_{\mathbf{t}}\right)=\sigma_{j j} \quad \text { se } t=s \text { e } 0 \text { caso contrário, }
\end{array}
$$

em que $i, j \in\{1,2, \ldots, J$.$\} e s, t \in\{1,2, \ldots, T$.$\} . Desse modo, tem-se que$ $\sigma_{j j}=\operatorname{var}\left(\epsilon_{j t}\right)+\operatorname{var}\left(\xi_{t}\right)$ e $\sigma_{j i}=\sigma_{i j}=\operatorname{var}\left(\xi_{t}\right)$, para $i \neq j$. Além da hipótese de ausência de autocorrelação nos termos de erro, representada por (19), assume-se, também, ortogonalidade e homoscedasticidade condicional dos termos de erro:

$$
E\left(\mathbf{u}_{\mathbf{t}} \mid \mathbf{X}_{\mathbf{t}}\right)=0
$$




$$
E\left(\mathbf{u}_{\mathbf{t}} \mathbf{u}_{\mathbf{t}}^{\top} \mid \mathbf{X}_{\mathbf{t}}\right)=\Omega
$$

em que $\mathbf{u}_{\mathbf{t}}^{\top}=\left[\mathbf{u}_{\mathbf{t}}^{1 \top} \mathbf{u}_{\mathbf{t}}^{2 \top} \ldots \mathbf{u}_{\mathbf{t}}^{\mathbf{J} \top}\right], \Omega=\Sigma \otimes I, I$ é a matriz identidade $(J \times J)$ e $\Sigma$ é a matriz de variância-covariância dos termos de erro:

$$
\Sigma=\left(\begin{array}{cccc}
\sigma_{11} & \sigma_{12} & \cdots & \sigma_{1 J} \\
\sigma_{21} & \sigma_{22} & \cdots & \sigma_{2 J} \\
\vdots & \vdots & \ddots & \vdots \\
\sigma_{J 1} & \sigma_{J 2} & \cdots & \sigma_{J J}
\end{array}\right)
$$

em que $\otimes$ é o produto de Kronecker. Como mostrado acima, uma vez que os choques de preferências são comuns a todas as equações (dado que impactam as decisões de consumo e compra de títulos do agente norte-americano representativo), a correlação entre os termos de erro das J equações é diferente de zero.

Cada equação j do sistema 15 pode ser estimada, individualmente, por MQO, porém a estimação via SUR proporciona ganhos de eficiência à estimação. O procedimento de estimação baseia-se no estimador MQG (Mínimos Quadrados Generalizados), que leva em consideração a correlação entre os termos de erros das diferentes equações (ZELLNER, 1962).

O estimador SUR é

$$
\hat{\beta}=\left[\mathbf{X}_{\mathbf{t}}^{\top} \Omega^{-1} \mathbf{X}_{\mathbf{t}}\right]^{-1} \mathbf{X}_{\mathbf{t}}^{\top} \Omega^{-1} \mathbf{R}_{\mathbf{t}}=\left[\mathbf{X}_{\mathbf{t}}^{\top}\left(\Sigma^{-1} \otimes \mathbf{I}\right) \mathbf{X}_{\mathbf{t}}\right]^{-1} \mathbf{X}_{\mathbf{t}}^{\top}\left(\Sigma^{-1} \otimes \mathbf{I}\right) \mathbf{R}_{\mathbf{t}}
$$

A matriz $\Sigma$ utilizada na estimação de $\hat{\beta}$, contudo, não é conhecida previamente, de modo que precisa ser estimada. Os resíduos da estimação MQO do modelo, portanto, são utilizados para a construção de um estimador consistente para $\Sigma$ :

$$
\hat{\sigma}_{i j}=s_{i j}=T^{-1} \sum_{t=1}^{T}\left(\hat{u}_{t j} \hat{u}_{t i}\right)
$$




$$
S \equiv\left(\begin{array}{cccc}
s_{11} & s_{12} & \cdots & s_{1 J} \\
s_{21} & s_{22} & \cdots & s_{2 J} \\
\vdots & \vdots & \ddots & \vdots \\
s_{J 1} & s_{J 2} & \cdots & s_{J J}
\end{array}\right)
$$

Usando-se S na estimação, assim, tem-se o estimador SUR - um estimador factível de Mínimos Quadrados Generalizados (MQG) -, que será igual ao estimador de máxima verossimilhança.

Esse estimador equivale assintoticamente ao estimador MQO nas seguintes situações, segundo Hayashi (2000):

1. Quando todas as equações possuem um conjunto de regressores comuns;

2. Quando ao menos uma equação possui um regressor não-comum e as equações não se relacionam entre si.

No modelo aqui proposto, a primeira situação não se verifica, uma vez que há somente um regressor comum a todas as equações $\left(\Delta y_{t}^{E U A}\right)$, com o outro regressor variando entre elas. Assim, a equivalência assintótica entre as estimações MQO e SUR somente ocorreria se as equações estimadas para os $J$ países não fossem relacionadas.

Conforme já argumentado, o modelo teórico aqui utilizado considera as decisões de um agente representativo dos Estados Unidos. Tal agente está sujeito a choques de preferência, estes que impactam as suas decisões de alocação de consumo. Concomitantemente, tais choques afetam igualmente os excessos de retorno de títulos de cada país j sobre um título norte-americano. Logo, tem-se um contexto de equações relacionadas, em que a estimação via SUR traz ganhos de eficiência em relação à estimação MQO equação por equação. 


\subsection{Dados}

\subsubsection{Construção dos Dados}

Os dados que serão aqui utilizados são provenientes da base International Financial Statistics (IFS), do Fundo Monetário Internacional (FMI). O período amostral utilizado contempla o primeiro trimestre de 1999 (1999T1) ao segundo trimestre de 2014 (2014T2). A escolha de uma periodicidade trimestral se deve ao fato de que tal frequência é mais compatível com a análise do ciclo de negócios, conforme colocado por Ferreira e Moore (2015). Além disso, uma maior frequência poderia trazer problemas em relação à heteroscedasticidade residual. Em relação à data inicial escolhida, tem-se que, ao fim dos anos 1990, países emergentes apresentam maior abertura econômica e financeira, bem como maior estabilidade econômica. O ano de 1999, além disso, marca o início da União Européia. Desse modo, 1999T1 torna-se um ponto natural de escolha.

A amostra de países do presente trabalho é diferente da amostra de Ferreira e Moore $(2015)^{11}$. Optou-se aqui por excluir as seguintes economias: Malásia, China, Índia, Dinamarca, Hong Kong e Rússia. Uma vez que grande parte do risco associado às moedas dos diferentes países deriva do fato de que estas podem se depreciar ou apreciar no momento de resgate do título comprado, tem-se que uma certa variabilidade das taxas de câmbio é necessária para o teste da teoria. Dessa maneira, excluiu-se as economias supracitadas da estimação por apresentarem regime de câmbio fixo ou bandas em algum momento do período amostral. Para tanto, baseou-se na classificação de facto de regimes de câmbio, disponibilizada pelo $\mathrm{FMI}^{12}$. China, Dinamarca, Hong Kong e Rússia apresentavam algum tipo de acordo de câmbio fixo, seja um regime de bandas cambiais, currency board ou outro acordo convencional. Os outros países, de acordo com o FMI, são classificados como independently floating ou managed floating with no pre-determined path for the exchange rate. A exclusão de Malásia e Índia da amostra baseou-se não na classificação de facto, mas no comportamento de seus dados: tais países apresentaram volatilidade cambial praticamente nula até o ano de 2005. A amostra utilizada possui,

\footnotetext{
11 A amostra dos autores engloba as moedas que representam cerca de $99 \%$ das transações bilaterais de câmbio de acordo com relatório do BIS (2013).

12 Utilizou-se a classificação de 2008.
} 
portanto, 22 países, estes apresentados nas Tabelas descritivas 1 e 2 .

Para a construção dos excessos de retorno de cada país ${ }^{13}$, extraiu-se as seguintes variáveis da base IFS: taxa de juros nominal para cada país j, taxa de câmbio (moeda doméstica do país j por US\$, fim de período) e o índice de preços ao consumidor norteamericano (CPI).

Em relação às taxas de juros, quando as taxas de juros de títulos de curto prazo (Treasury Bills) não estavam disponíveis, optou-se pela utilização de taxas de depósito ${ }^{14}$. Quando estas também não estavam disponíveis, utilizou-se as taxas de títulos de longo prazo do governo (government bonds).

Optou-se, por questões metodológicas, pela construção inicial dos excessos de retorno em frequência mensal, para a posterior obtenção da série trimestral. Calcula-se os excessos de retorno de acordo com o modelo teórico apresentado em capítulo anterior, ou seja, do ponto de vista de um agente norte-americano: em outras palavras, o excesso de retorno de títulos estrangeiros em relação a títulos dos EUA. Os excessos de retorno mensais, assim, são construídos a partir da seguinte fórmula, apresentada em Ferreira e Moore (2015) e derivada do modelo teórico apresentado:

$$
R_{t+k}^{j e} \equiv\left\{\left[\left(1+i_{t . k}^{j}\right)\left(S_{t}^{j / U S \$} / S_{t+k}^{j / U S \$}\right)-\left(1+i_{t . k}^{E U A}\right)\right]\left(P_{t}^{E U A} / P_{t+k}^{E U A}\right)\right\}
$$

em que $i_{t . k}^{j}$ é a taxa de juros paga pelo título do país j comprado em $\mathrm{t}$, com vencimento em $\mathrm{t}+\mathrm{k} ; P_{t}^{E U A}$ é o CPI norte-americano e $S_{t}^{j / U S \$}$ é a taxa de câmbio de fim de período do país j definida como o preço doméstico da moeda estrangeira, no caso, o dólar americano. $R_{t+k}^{j e}$ é o excesso de retorno ex-post de um título do país j em relação a um título dos EUA, ambos adquiridos em t, com vencimento em $\mathrm{k}$.

Suponha que as taxas de juros utilizadas se referem às taxas de um título com vencimento em um mês, ou seja, $\mathrm{k}=1$. Usando-se valores aproximados, o exemplo descrito

13 A teoria apresentada baseia-se nos excessos de retorno esperados, porém, para a estimação, utiliza-se os excessos de retorno ex post.

14 Austrália, Singapura, Tailândia e Turquia possuem dados de Treasury Bills disponíveis, porém a amplitude da amostra é menor do que a desejada, de modo que, para esses países, opta-se, também, pela utilização de taxas de depósito 
abaixo ilustra a forma de construção dos excessos de retorno mensais. Considere o caso do Brasil, cuja taxa de juros nominal de Dezembro de 1999 é de 1,6\%a.m. Um título adquirido nos EUA, também em Dezembro de 1999, possui taxa de juros de 0,41\%a.m. Assume-se que esses valores se referem ao fim de período, de maneira que os títulos descritos pagarão os juros prometidos ao final de Janeiro de 2000. A variação da taxa de câmbio ex post entre Dezembro de 1999 e Janeiro de 2000 foi de 0,74\% e a mudança ex post no nível de preços norte-americano, para o mesmo período, foi de 0,29\%. Substituindo-se tais valores na fórmula acima, encontra-se um excesso de retorno de aproximadamente 0,41\%a.m. Em outras palavras, um título brasileiro pagou cerca de 0,41\%a.m. a mais que um título americano em Janeiro de 2000, já considerando a variação cambial, sendo ambos adquiridos ao fim do mês anterior.

Como em Ferreira e Moore (2015), para se obter os excessos de retorno trimestrais, calcula-se a média dos excessos de retorno mensais para cada trimestre e, utilizando-se juros simples (multiplica-se a média encontrada por 12), obtém-se a série em percentagem anual. Como exemplo, utiliza-se, novamente, a economia brasileira. Conforme supracitado, o excesso de retorno de um título brasileiro em Janeiro de 2000 foi de 0,41\%a.m. Para Fevereiro e Março de 2000, os excessos de retorno calculados foram, respectivamente, de 2,95\%a.m. e 2,21\%a.m. Calculando-se a média mensal para o período, tem-se um excesso de retorno trimestral de 1,86\%a.m. Capitalizando-se essa taxa via juros simples, o excesso de retorno de 2000T1 será de 22,33\%a.a.

A partir da metodologia descrita, construiu-se as séries de excessos de retorno trimestrais para os 22 países da amostra. As séries construídas englobam o período de 1999T1 a 2014T2. É importante salientar que, somente para o caso da Alemanha, a primeira observação do excesso de retorno trimestral, em 1999T1, foi construída a partir da média mensal apenas dos meses de Fevereiro e Março. Isso pois a construção do excesso de retorno de Janeiro de 1999 utiliza a variação cambial referente à última cotação mensal do marco e a primeira cotação mensal após a unificação monetária da Europa. Como estas não são comparáveis, exclui-se a primeira observação da série mensal para evitar uma contaminação dos dados. 
Por fim, no que diz respeito às variáveis dependentes que serão aqui utilizadas, as taxas de crescimento do PIB dos diferentes países são obtidas a partir dos dados de um índice trimestral do PIB real, 2010=100, também extraídos da base IFS. As taxas de crescimento do PIB são obtidas calculando-se a variação do índice no período: $\ln \left(P I B_{T}\right)-$ $\ln \left(P I B_{T-1)}\right)$, sendo $\mathrm{T}$ um indicador de trimestre.

Para a maioria dos países da amostra, os dados referentes ao índice do PIB trimestral não apresentavam correção para a sazonalidade. Nesses casos, portanto, utilizou-se o método multiplicativo de ajuste sazonal trimestral X-12: Brasil, Chile, Hungria, Indonésia, Israel, Coréia, Noruega, Peru, Singapura, Suécia, Tailândia e Turquia.

\subsubsection{Estatísticas Descritivas}

Na presente seção, apresenta-se algumas estatísticas descritivas das principais variáveis utilizadas no trabalho. Na tabela 1, observa-se os dados referentes à taxa de crescimento trimestral do PIB dos diferentes países.

Singapura apresentou a maior média do período (cerca de 1,39\% por trimestre). Com a menor média de taxa de crescimento, tem-se o Japão (apenas 0,19\% no trimestre). Em relação ao desvio padrão da variação do PIB trimestral, México e Colômbia apresentaram as maiores variabilidades enquanto Austrália e África do Sul tiveram os menores valores de desvio padrão no período.

Na tabela 2, apresenta-se as estatísticas descritivas para as séries de excessos de retorno trimestrais. Observa-se que os excessos de retorno assumem valores muito grandes, tanto positivos como negativos. A variabilidade desses retornos também é bastante elevada, com destaque para o desvio padrão de retornos em excesso de títulos brasileiros, de 36,29 pontos percentuais; e de títulos turcos, de 34,22 pontos percentuais.

Apenas o Japão apresentou valores médios negativos de excessos de retorno. Em outras palavras, pode-se dizer que, em relação aos títulos japoneses, os títulos norteamericanos apresentaram, em média, retorno mais elevado, levando-se em conta a variação cambial do período. Os maiores excessos de retorno médios ocorrem, também, na Turquia e no Brasil: 13,03\% e 9,47\%, respectivamente. 
Tabela 1: Crescimento trimestral do PIB (em \%) - estatísticas descritivas

\begin{tabular}{lcccc}
\hline \multicolumn{1}{c}{ Séries } & Média & Desvio Padrão & Mín. & Máx. \\
\hline Austrália & 0.74 & 0.49 & -0.82 & 1.64 \\
Brasil & 0.75 & 1.15 & -3.81 & 2.73 \\
Canadá & 0.59 & 0.63 & -2.25 & 1.61 \\
Chile & 1.04 & 0.99 & -1.40 & 4.19 \\
Colômbia & 0.66 & 2.62 & -18.14 & 4.17 \\
Alemanha & 0.32 & 0.91 & -4.48 & 2.11 \\
Hungria & 0.52 & 1.00 & -3.60 & 2.60 \\
Indonésia & 1.31 & 0.64 & -0.49 & 2.64 \\
Israel & 0.89 & 1.32 & -1.86 & 3.44 \\
Japão & 0.19 & 1.12 & -3.97 & 2.64 \\
Coréia & 1.11 & 1.44 & -2.95 & 7.81 \\
México & 0.63 & 3.02 & -7.29 & 6.89 \\
Nova Zelândia & 0.69 & 0.92 & -1.66 & 3.17 \\
Noruega & 0.47 & 2.05 & -3.61 & 7.21 \\
Peru & 1.27 & 1.31 & -1.48 & 4.83 \\
Singapura & 1.39 & 2.08 & -3.70 & 6.84 \\
África do Sul & 0.81 & 0.59 & -1.62 & 1.79 \\
Suécia & 0.55 & 1.16 & -3.74 & 3.25 \\
Suíça & 0.50 & 0.60 & -1.86 & 2.11 \\
Tailândia & 1.02 & 2.51 & -11.19 & 12.07 \\
Turquia & 0.95 & 2.37 & -5.53 & 4.97 \\
Reino Undio & 0.47 & 0.68 & -2.23 & 1.63 \\
Estados Unidos & 0.51 & 0.67 & -2.11 & 1.89 \\
\hline
\end{tabular}

Fonte: elaboração própria a partir de dados do FMI. Nota: 63 observações. Para África do Sul, Indonésia e Singapura, 62 observações.

A partir dos gráficos 1, 2, 3 e 4, observa-se que há diferentes comportamentos dos excessos de retornos dos países em relação ao PIB norte-americano. Nos momentos de recessão norte-americana, representados pela área hachurada do gráfico ${ }^{15}$, os excessos de retorno de Japão e Suíça são elevados, conforme se depreende das figuras 2 e 3. Títulos brasileiros e turcos, por sua vez, apresentaram excessos de retorno menores (inclusive negativos) nos períodos de recessão dos EUA.

Tal comportamento é observado principalmente na recessão de 2008: títulos japoneses e suíços pagavam excessos de retorno mais elevados no período, funcionando como um seguro contra a crise norte-americana; enquanto títulos brasileiros e turcos tiveram excessos de retorno reduzidos, sendo considerados títulos mais arriscados.

$\overline{15}$ De acordo com o indicador de recessão dos EUA do NBER - National Bureau of Economic Research 
Tabela 2: Excessos de Retorno (em \%) - estatísticas descritivas

\begin{tabular}{lrrrr}
\hline Séries & Média & Desvio Padrão & Mín. & Máx. \\
\hline Austrália & 4.88 & 25.40 & -68.67 & 71.01 \\
Brasil & 9.47 & 36.29 & -89.80 & 89.67 \\
Canadá & 2.80 & 16.67 & -53.65 & 36.55 \\
Chile & 1.90 & 23.40 & -60.49 & 53.46 \\
Colômbia & 4.64 & 27.30 & -58.03 & 72.86 \\
Alemanha & 2.42 & 21.29 & -35.75 & 58.34 \\
Hungria & 6.22 & 30.07 & -69.75 & 86.94 \\
Indonésia & 6.42 & 32.67 & -68.92 & 137.42 \\
Israel & 3.70 & 16.18 & -37.78 & 40.89 \\
Japão & -1.09 & 21.91 & -43.11 & 57.50 \\
Coréia & 4.04 & 19.34 & -50.63 & 45.65 \\
México & 4.07 & 20.07 & -79.15 & 40.81 \\
Nova Zelândia & 6.05 & 25.39 & -53.70 & 64.55 \\
Noruega & 3.52 & 23.01 & -67.25 & 73.99 \\
Peru & 2.65 & 10.40 & -28.61 & 36.13 \\
Singapura & 0.42 & 10.33 & -21.17 & 25.05 \\
África do Sul & 3.13 & 33.91 & -106.99 & 96.32 \\
Suécia & 1.62 & 23.24 & -48.73 & 62.39 \\
Suíça & 1.67 & 21.53 & -33.71 & 53.50 \\
Tailândia & 1.36 & 14.40 & -41.29 & 36.29 \\
Turquia & 13.03 & 34.22 & -98.18 & 117.58 \\
Reino Unido & 1.18 & 18.98 & -79.73 & 59.63 \\
\hline
\end{tabular}

Fonte: elaboração própria a partir de dados do FMI. Nota: 63 observações. Todas as estatísticas definidas em pontos percentuais.

Figura 1: Excesso de retorno Brasil X Ciclo NBER

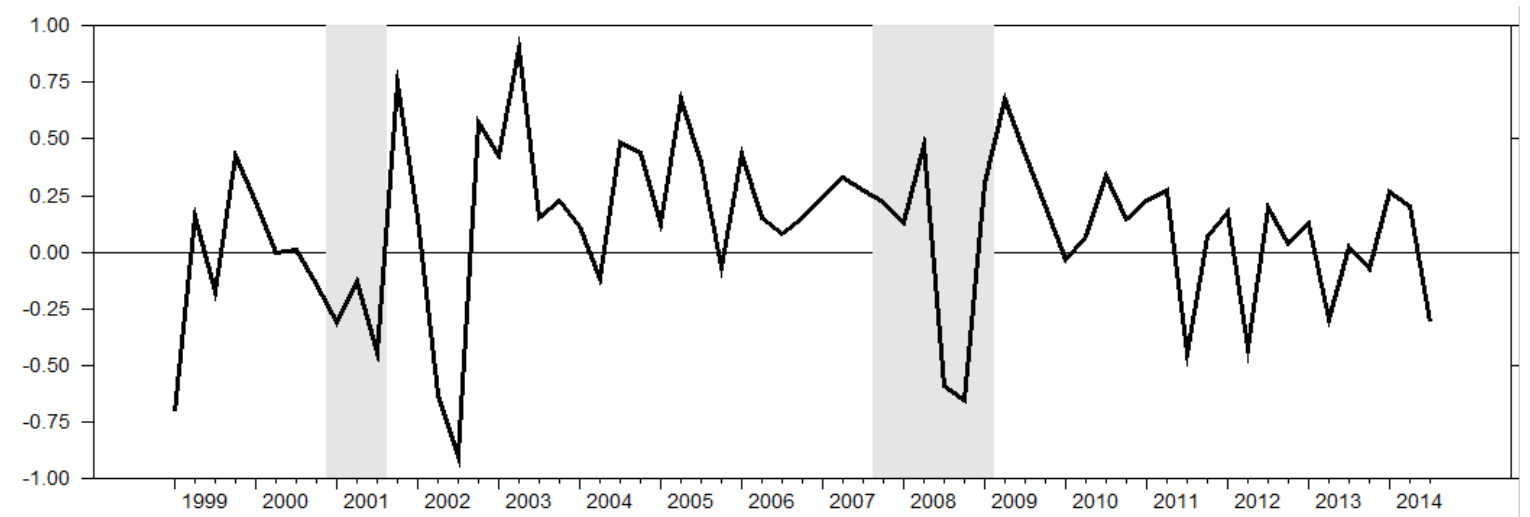

Fonte: elaboração própria a partir de dados do FMI e do NBER. 
Figura 2: Excesso de retorno Japão X Ciclo NBER

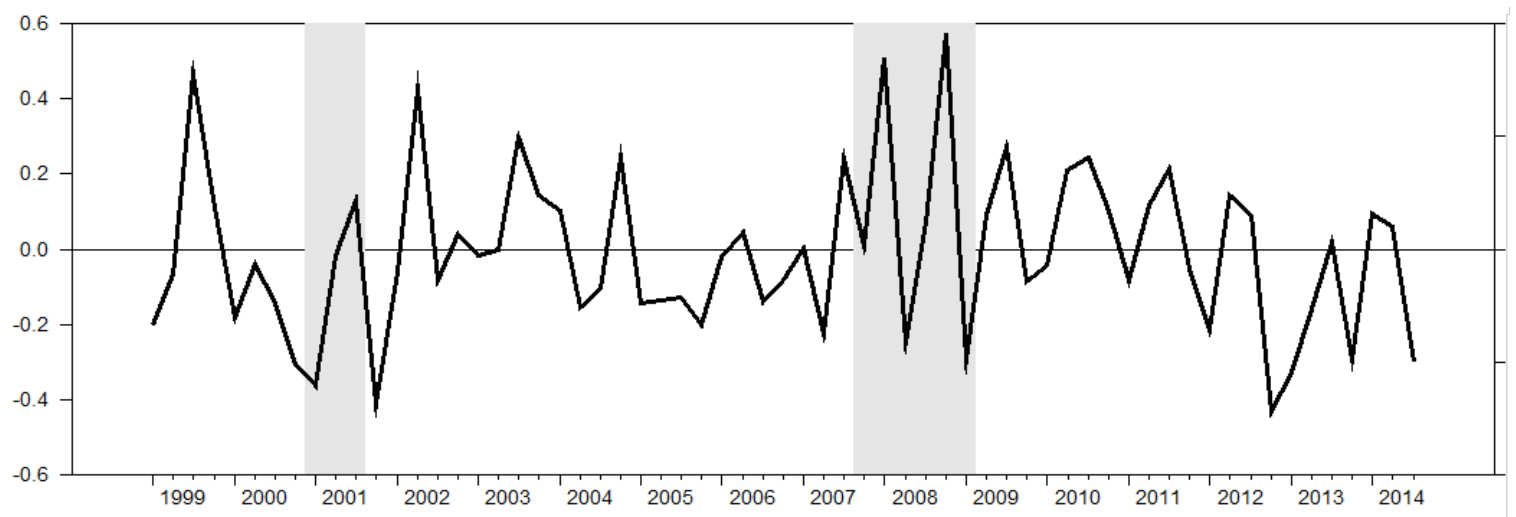

Fonte: elaboração própria a partir de dados do FMI e do NBER.

Figura 3: Excesso de retorno Suíça X Ciclo NBER

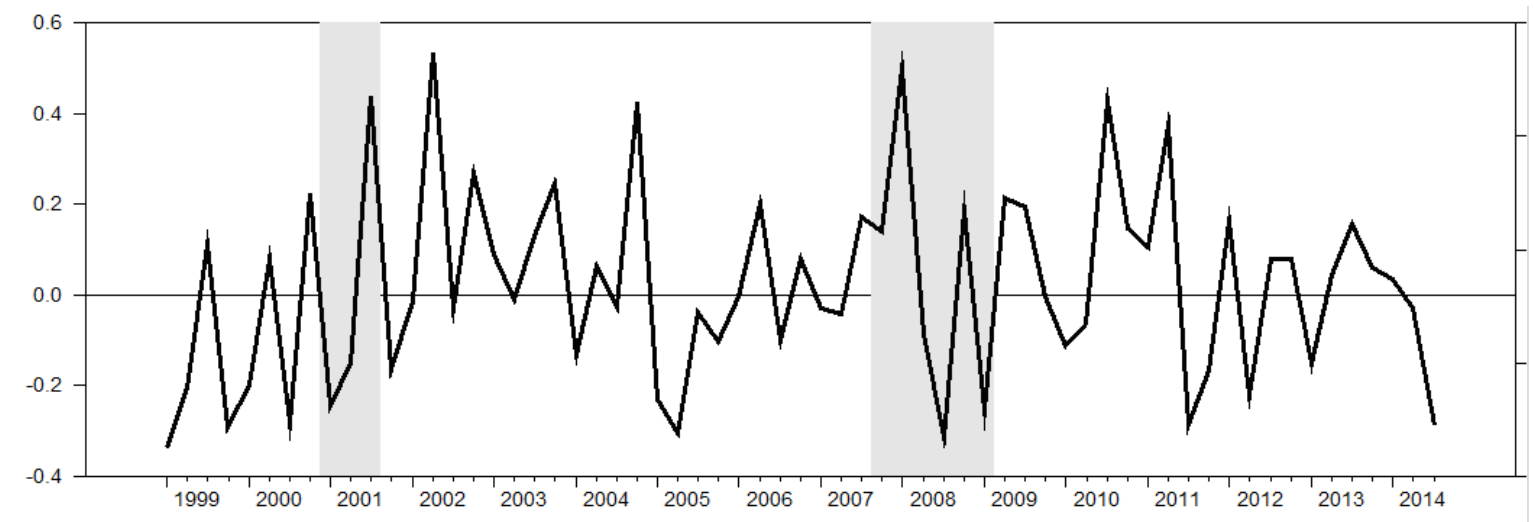

Fonte: elaboração própria a partir de dados do FMI e do NBER.

Figura 4: Excesso de retorno Turquia X Ciclo NBER

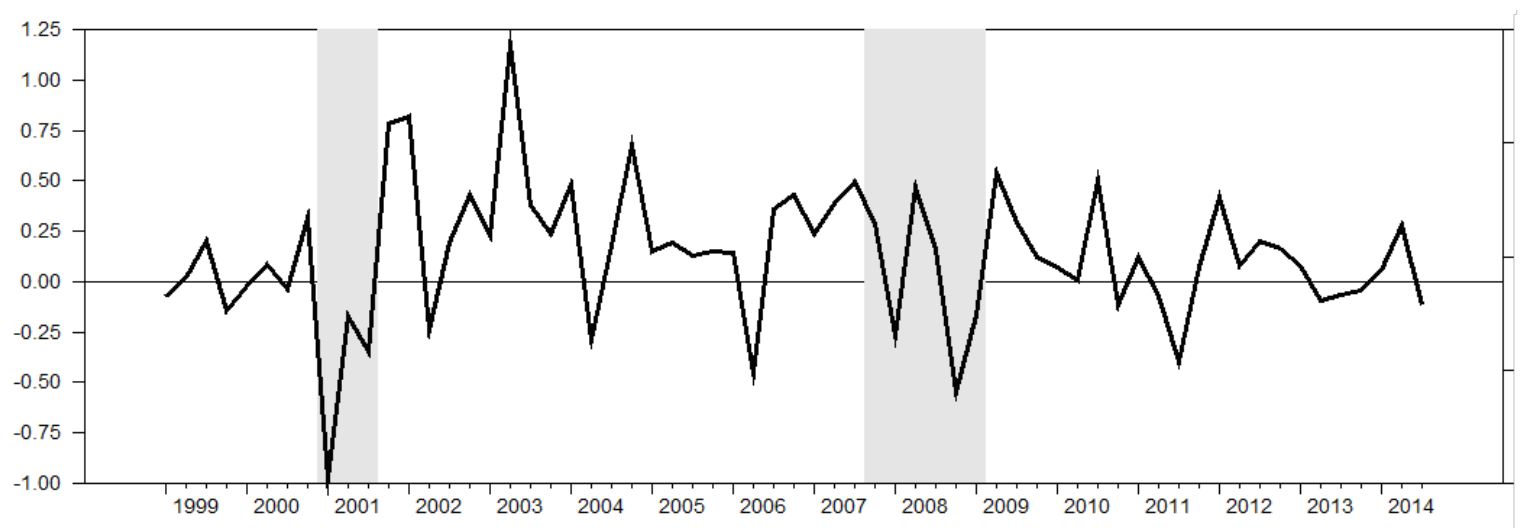

Fonte: elaboração própria a partir de dados do FMI e do NBER. 


\subsection{Consumo X PIB}

Na seção 2.3 do capítulo 2.1, assumiu-se a hipótese de compartilhamento total de riscos e equilíbrio simétrico do modelo de Lucas (1982) de dois países. Dessa forma, pode-se utilizar a taxa de crescimento do PIB dos países como proxy para o consumo nas estimações econométricas. A estimação do modelo definido pela equação 14 inclui, portanto, as taxas de crescimento do PIB dos países doméstico (EUA) e estrangeiro (país j) como fatores de risco no lugar dos fatores de consumo.

Pode-se pensar na hipótese imposta como pouco realista, já que i) economias de dotação são pouco prováveis; e ii) em um equilíbrio simétrico, questiona-se a própria existência de excessos de retorno entre títulos de diferentes países. Incluir uma economia de produção no modelo, contudo, mesmo que mais realista, não mudaria as condições necessárias para se entender o problema de precificação de ativos, uma vez que este se baseia nas equações de Euler obtidas via otimização do consumidor. Assim, embora economias de dotação sejam pouco condizentes com a realidade de economias de produção, o modelo apresentado possui a vantagem de que a dinâmica do consumo -e, logo, do produto- é dada exogenamente, sem alterar as implicações do problema de precificação.

É razoável supor, ainda, que o consumo de bens domésticos de um país seja uma porcentagem de seu PIB. Ao mesmo tempo, o consumo de bens importados também corresponderia a uma fração do que é produzido no país estrangeiro, uma hipótese razoável uma vez que a demanda observada é gerada por algum produto.

Busca-se, assim, nesta seção, analisar como a proporção de consumo em relação ao PIB se comporta ao longo do tempo, utilizando-se dados da economia norte-americana. Os dados de consumo são provenientes da base de dados Data Stream $^{16}$ e o PIB norteamericano está disponível no site da BEA (Bureau of Economic Analysis - U.S. Department of Commerce). Ambas variáveis são nominais e estão em uma frequência trimestral, de 1999T1 a 2013T1. A figura 5 apresenta a série da razão entre Consumo Doméstico e PIB dos EUA.

16 Os dados do Data Stream são os mesmos utilizados por Ferreira e Moore (2015) em seu trabalho. 
Figura 5: Consumo Doméstico / PIB ao longo do tempo: EUA

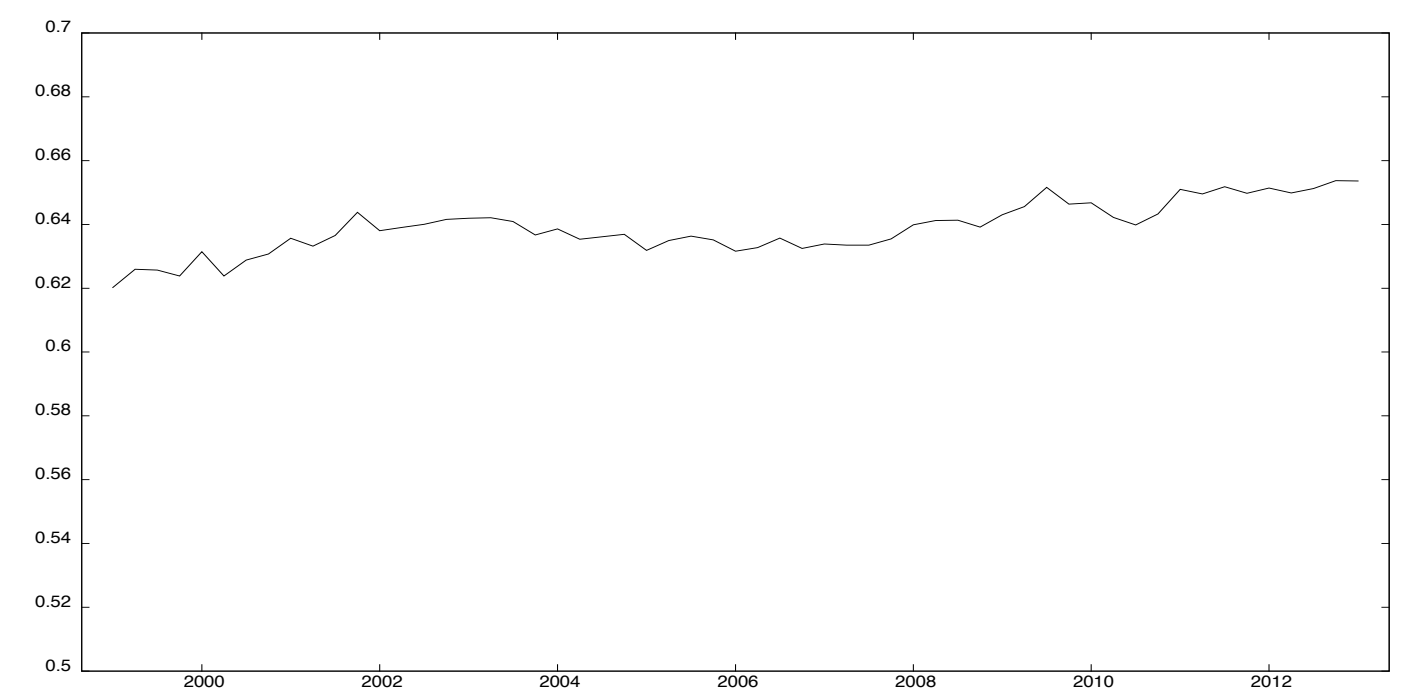

Fonte: elaboração própria a partir de dados do Data Stream e da BEA.

Observa-se que a série apresenta poucas oscilações, mantendo-se ao redor do valor de 0,63. Em outras palavras, o consumo doméstico dos EUA é de cerca de $63 \%$ do PIB doméstico. O valor da proporção do consumo em relação ao PIB não altera a interpretação do modelo linear: os resultados com o PIB como fator de risco possuem interpretação análoga ao resultados do modelo com os fatores de consumo.

\section{Resultados}

No presente capítulo, apresenta-se os resultados provenientes da estimação da equação 14. Primeiramente, o modelo será estimado por mínimos quadrados ordinários, a fim de se compará-lo com a estimação subsequente do modelo via SUR.

Opta-se, aqui, por apresentar os resultados graficamente, devido a sua melhor visualização. Discute-se, também, a significância dos parâmetros encontrados. É importante ressaltar que os coeficientes $\beta_{1}^{j}$ e $\beta_{2}^{j}$ da equação 14 são os betas referentes ao consumo de bens domésticos (dos EUA) e ao consumo de bens importados de cada país j da amostra, representados, nesse modelo, pelas taxas de crescimento do PIB dos EUA e do PIB de cada país j, respectivamente.

Em relação ao sinal dos coeficientes estimados, têm-se a seguinte interpretação: 
parâmetros positivos implicam que, diante de alterações negativas no crescimento do PIB (estas que se refletem no consumo do agente), o excesso de retorno de títulos do país j em relação aos títulos norte-americanos tende a ser menor; ou seja, títulos do país j são considerados arriscados, pagando menos em momentos ruins da economia. Betas negativos, por sua vez, implicam um comportamento contra-cíclico dos excessos de retorno de títulos do país j, sendo maiores em momentos de retração do crescimento. Tais títulos, assim, agiriam como um seguro contra oscilações do PIB e do consumo ${ }^{17}$.

\subsection{Resultados preliminares: estimações MQO}

Para a estimação do modelo linear por mínimos quadrados ordinários, estima-se, separadamente para cada país $j$, a equação 14. Os resultados são obtidos tanto para o modelo que inclui os dois fatores de risco $\left(\Delta y_{t}^{E U A}\right.$ e $\left.\Delta y_{t}^{j}\right)$ - o que se chama aqui de modelo condicional-, como para modelos que chamaremos de incondicionais, que incluam somente um destes fatores.

Os betas estimados por MQO para o modelo condicional são apresentados nas figuras 6 e 7. O eixo vertical dos gráficos representa os valores assumidos pelos betas estimados para cada país j da amostra. O eixo horizontal, por sua vez, distribui os países em ordem crescente de taxa de juros. Deseja-se, com essa ordenação, verificar se os países com maiores taxas de juros médias são, de fato, aqueles com maiores quantidades de risco estimadas (maiores coeficientes). Todos os resultados apresentados seguem esse padrão.

Em relação ao coeficiente $\hat{\beta}_{1}^{j}$ de cada país, observa-se que este é positivo para a maioria dos países da amostra. Observa-se que os países cujas médias de taxas de juros são maiores (Turquia e Brasil, por exemplo) possuem coeficientes relativamente mais altos, indicando títulos mais arriscados quando comparados aos títulos norte-americanos. Japão, Singapura e Suíça, com as menores médias de taxas de juros, apresentam parâmetros negativos ou relativamente próximos de zero. Em relação ao restante da amostra, em posição intermediária na classificação de média de taxa de juros, há comportamentos distintos.

$\overline{17}$ Lembrando que toda a análise é feita do ponto de vista de um agente norte-americano. 
Figura 6: Estimação MQO com 2 fatores: $\hat{\beta}_{1}^{j}$

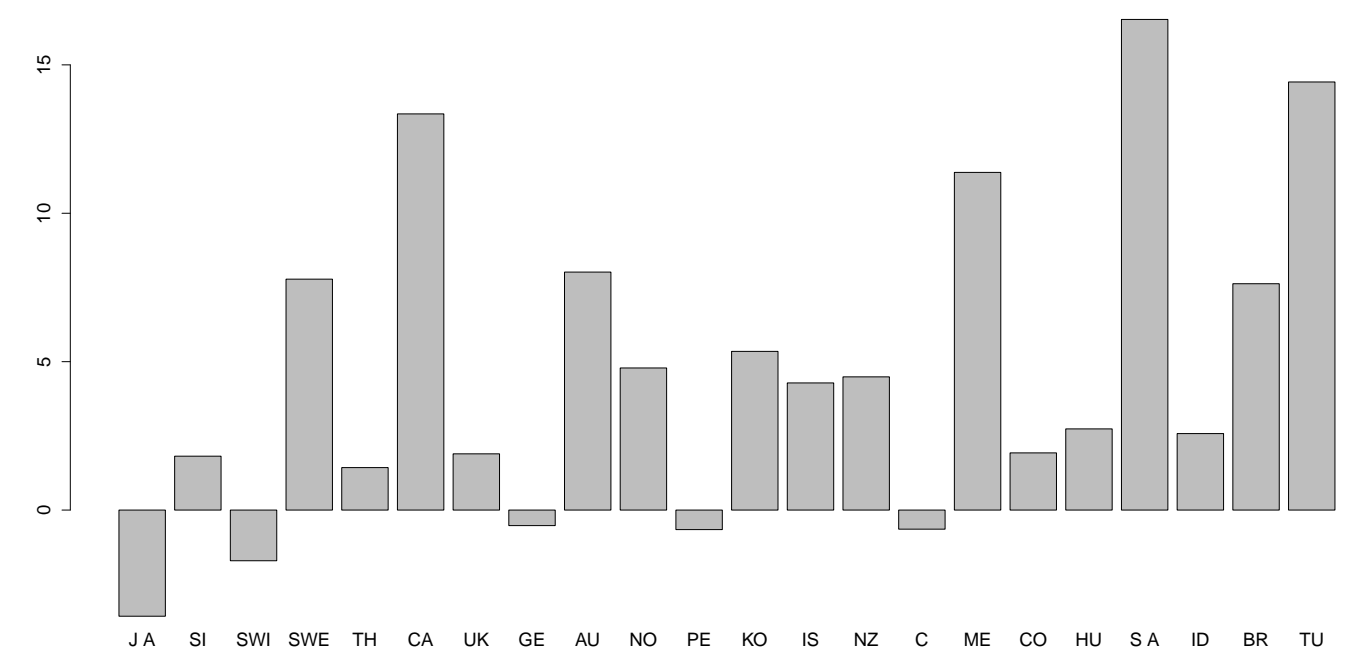

Fonte: elaboração própria.

Para o parâmetro $\hat{\beta}_{2}^{j}$ estimado para cada economia da amostra, não se observou nenhum padrão específico de comportamento dos coeficientes em relação à média das taxas de juros.

Figura 7: Estimação MQO com 2 fatores: $\hat{\beta}_{2}^{j}$

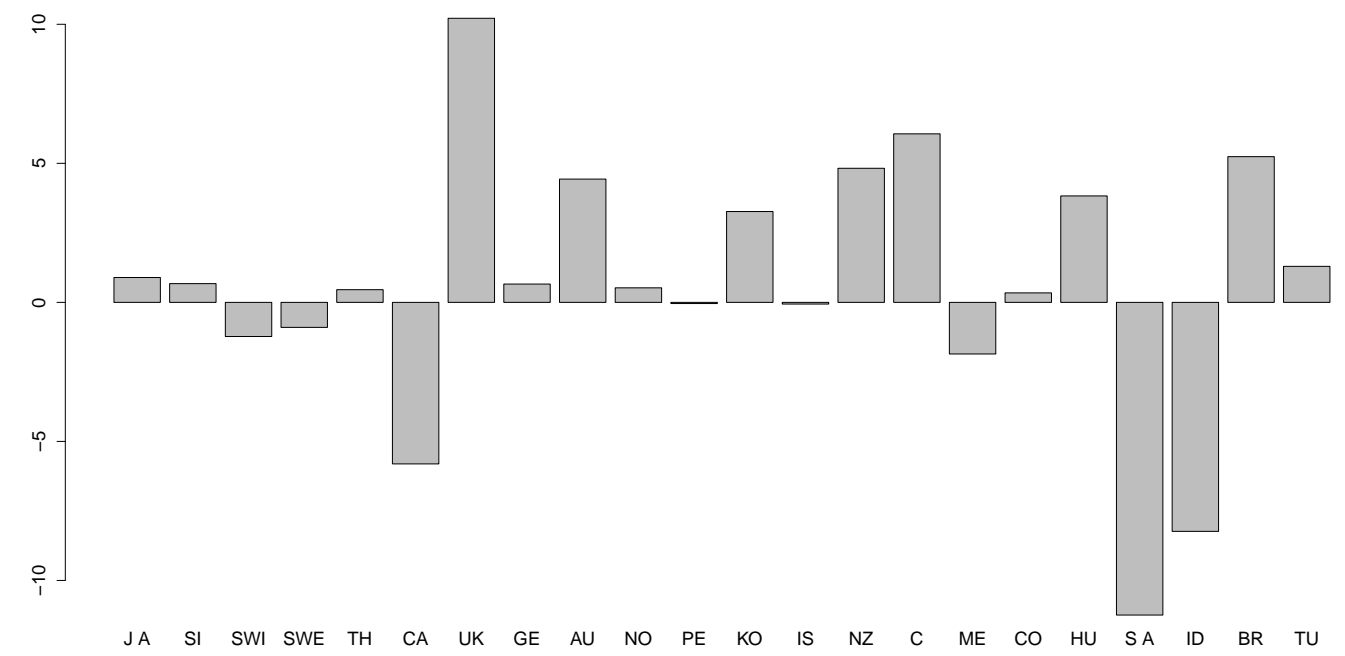

Fonte: elaboração própria.

No que diz respeito à significância dos parâmetros estimados, têm-se que cinco dos coeficientes $\beta_{2}^{j}$ estimados são significantes a um nível de $15 \%^{18}$ e, destes, quatro o 18 Utiliza-se, no presente trabalho, níveis de significância dos betas estimados de $15 \%$ e $10 \%$ com 
são ao nível de 10\%. Para os coeficientes $\beta_{1}^{j}$ estimados, as mesmas quantidades de betas significantes se aplicam. Os parâmetros são significantes conjuntamente ao nível de 15\% em oito equações, e ao nível de $10 \%$ em seis delas.

Para os modelos incondicionais, os betas estimados são apresentados nos gráficos 8 e 9. Novamente, os países estão em ordem crescente de média de taxa de juros.

Para o modelo estimado apenas com a variável $\Delta y_{t}^{E U A}$, observa-se que o comportamento dos parâmetros $\beta_{1}^{j}$ estimados não difere muito do que era observado no modelo condicional. Turquia, África do Sul e Brasil se encontram na parte superior da distribuição de média de taxas de juros e possuem as quantidades de risco de maior magnitude. Japão, Singapura e Suíça estão na distribuição inferior, apresentando coeficientes estimados negativos ou de menor magnitude. Em relação à parte intermediária da distribuição, não se infere comportamento específico. Ademais, bem como no modelo condicional, os coeficientes $\beta_{2}^{j}$ produzidos pelo modelo com apenas $\Delta y_{t}^{j}$ também não apresentam nenhum comportamento padrão em relação às taxas de juros.

Figura 8: Estimação MQO com 1 fator: $\hat{\beta}_{1}^{j}$

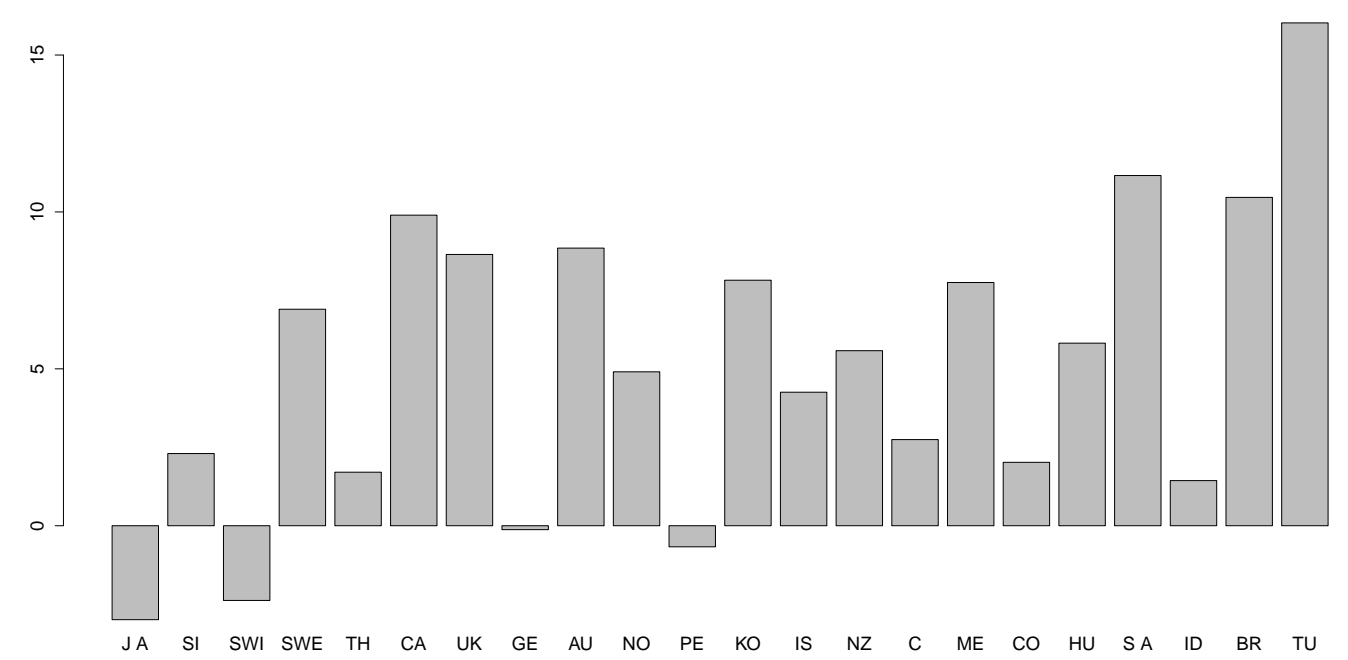

Fonte: elaboração própria.

Em relação à significância dos parâmetros estimados pelo modelo incondicional, têm-se que, em nove das vinte e duas equações estimadas, os coeficientes $\hat{\beta}_{2}^{j}$ são signifi-

o objetivo de facilitar a comparação com os resultados de Ferreira e Moore (2015), que também apresentam tais valores. 
Figura 9: Estimação MQO com 1 fator: $\hat{\beta}_{2}^{j}$

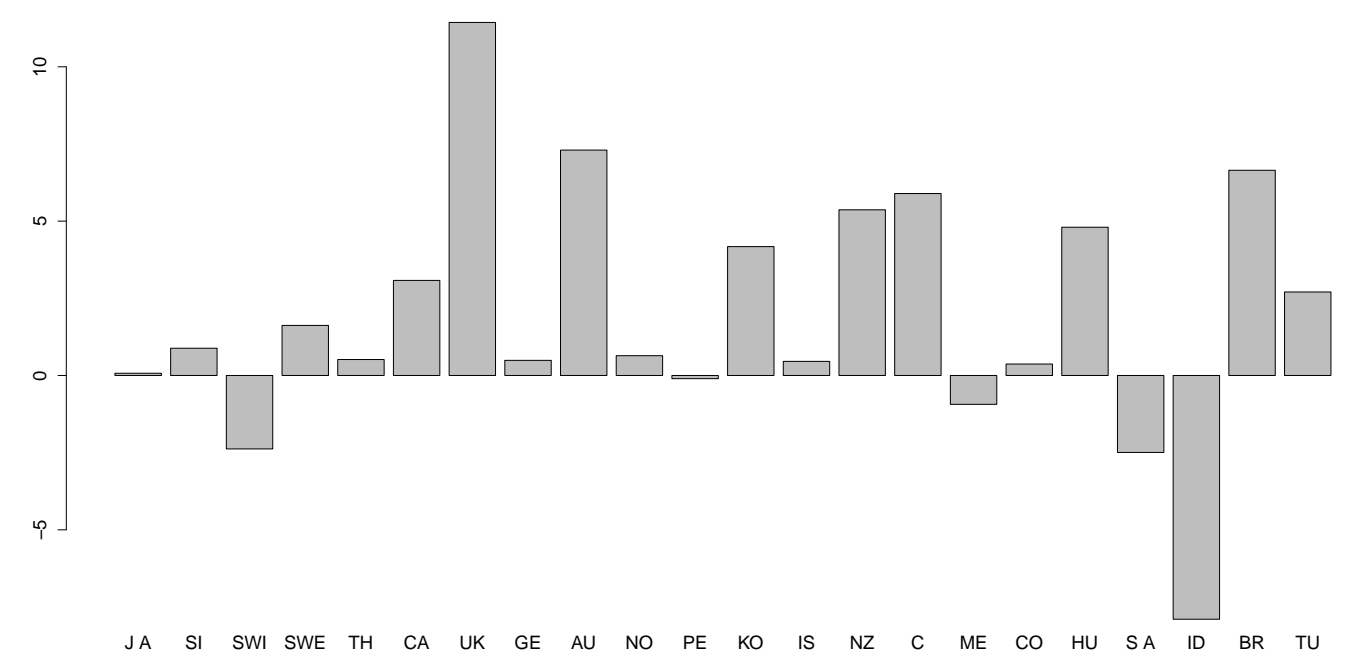

Fonte: elaboração própria.

cantes ao nível de $15 \%$. Destes, sete o são a $10 \%$. Para os parâmetros estimados $\beta_{1}^{j}$, seis equações apresentaram coeficientes significantes a 15\%, sendo quatro destes significativos ao nível de $10 \%$.

\subsection{Estimações SUR}

Na presente seção, apresenta-se os resultados da estimação simultânea da equação 14 para os 22 países da amostra, via SUR -Seemingly Unrelated Regressions.

Observa-se na figura 10, novamente, que economias com médias de taxa de juros menores (Japão, Suíça, Singapura) encontram-se na distribuição inferior da figura. Economias cujas taxas de juros são mais altas, em média, apresentaram quantidades de risco estimadas mais elevadas, conforme já ocorria com os modelos MQO estimados anteriormente.

No que diz respeito à figura 11, continua não havendo padrão comportamental que associe a quantidade de risco estimada $\beta_{2}^{j}$ e a média das taxas de juros.

Para se corroborar as inferências visuais, estimou-se regressões MQO dos betas estimados sobre as médias de taxas de juros e sobre a posição dos países na classificação 
Figura 10: Estimação SUR: $\hat{\beta}_{1}^{j}$

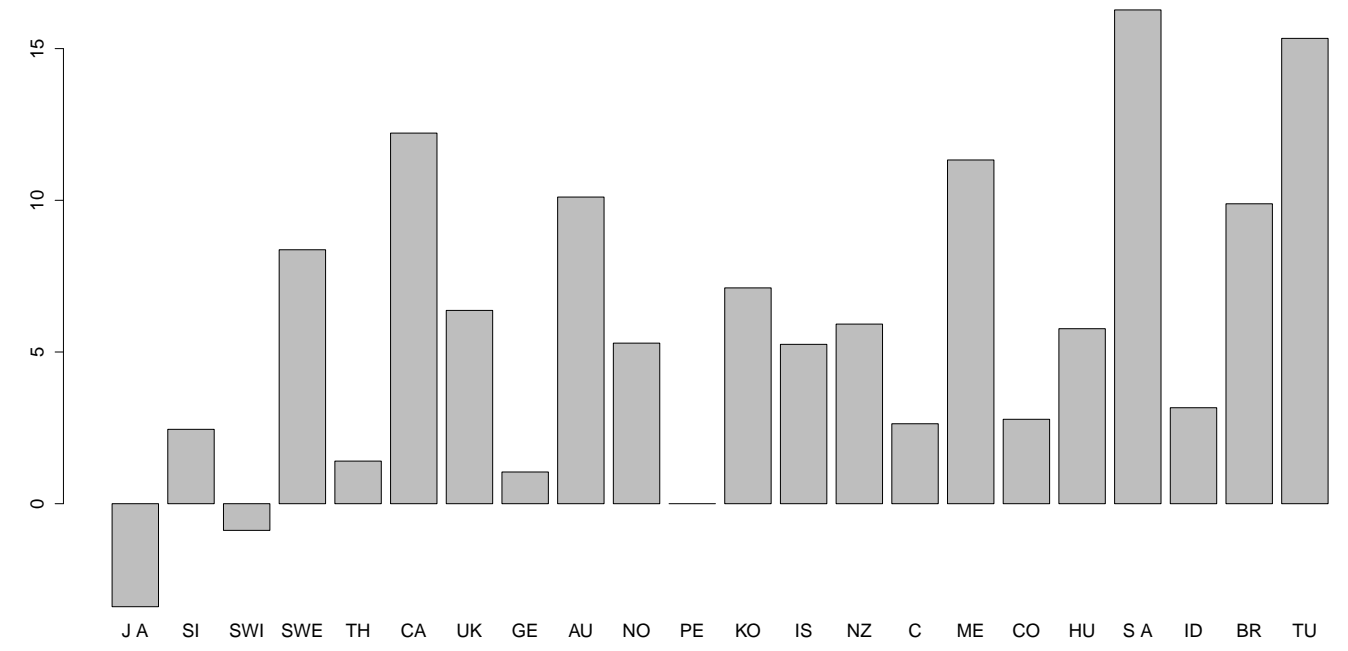

Fonte: elaboração própria.

Figura 11: Estimação SUR: $\hat{\beta}_{2}^{j}$

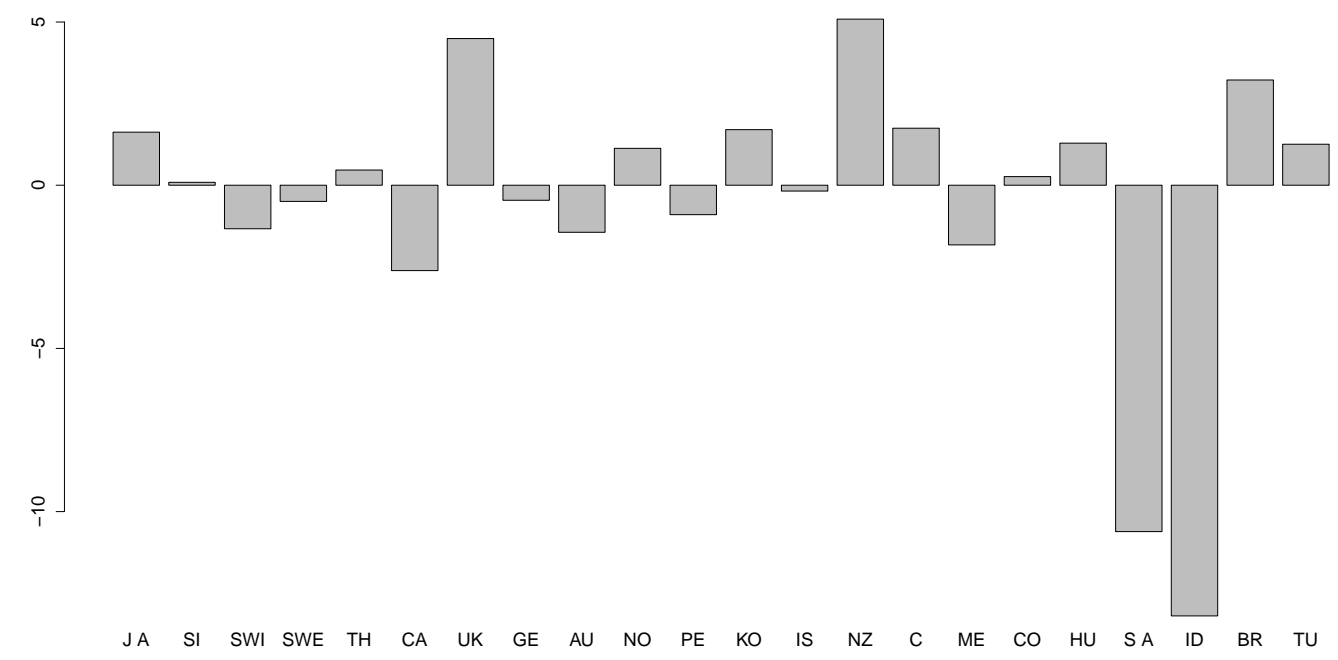

Fonte: elaboração própria. 
de médias de taxas de juros ${ }^{19}$. Os resultados são apresentados na tabela 3 .

Tabela 3: Regressão dos Betas sobre Médias de Taxa de Juros e Posições no Rank

\begin{tabular}{|c|c|c|c|c|}
\hline Variáveis Explicativas & \multicolumn{4}{|c|}{ Variável Dependente } \\
\hline SUR Amostra Total & \multicolumn{2}{|c|}{$\hat{\beta}_{2}^{j}$} & \multicolumn{2}{|c|}{$\hat{\beta_{1}^{j}}$} \\
\hline Constante & -0.26390 & 1.26299 & $3.13969 * *$ & 1.18438 \\
\hline Média Tx. Juros & -0.03575 & - & $0.43444 * * *$ & - \\
\hline Posição no Rank & - & -0.15208 & - & $0.40467 * *$ \\
\hline MQO - 2 fatores & \multicolumn{2}{|c|}{$\hat{\beta}_{2}^{j}$} & \multicolumn{2}{|c|}{$\hat{\beta_{1}^{j}}$} \\
\hline Constante & 0.79194 & 1.48247 & 2.08907 & 0.44037 \\
\hline Média Tx. Juros & -0.02989 & - & $0.41909 * *$ & - \\
\hline Posição no Rank & - & -0.07620 & - & $0.36992 * *$ \\
\hline MQO - 1 fator & \multicolumn{2}{|c|}{$\hat{\beta}_{2}^{j}$} & \multicolumn{2}{|c|}{$\hat{\beta_{1}^{j}}$} \\
\hline Constante & 1.95270 & 2.22609 & $2.31509 *$ & 0.85934 \\
\hline Média Tx. Juros & -0.00220 & - & $0.44747 * * *$ & - \\
\hline Posição no Rank & - & -0.02496 & - & $0.36837 * *$ \\
\hline SUR Robustez & \multicolumn{2}{|c|}{$\hat{\beta_{2}^{j}}$} & \multicolumn{2}{|c|}{$\hat{\beta_{1}^{j}}$} \\
\hline Constante & 2.37161 & 1.24641 & 2.45195 & -0.58208 \\
\hline Média Tx. Juros & -0.36414 & - & $0.83758 * *$ & - \\
\hline Posição no Rank & - & -0.20034 & - & $1.24403 * *$ \\
\hline
\end{tabular}

Observa-se que uma regressão dos coeficientes $\hat{\beta}_{1}^{j}$ dos países sobre suas médias de taxas de juros mais uma constante revela um intercepto significante a $5 \%$ de 3,14 e uma inclinação positiva e significante a $1 \%$ de 0,43. Em outras palavras, uma mudança positiva de um ponto percentual na média de taxa de juros aumenta a quantidade de risco estimada em 0,43. Em relação à regressão sobre a posição na classificação e uma constante, tem-se um intercepto não-significante de 1,18 e uma inclinação positiva de 0,40, significativa ao nível de $5 \%$. No que diz respeito às regressões dos coeficientes $\hat{\beta}_{2}^{j}$, nenhuma delas apresentou parâmetros significativos (tanto usando a média do juros como a posição na classificação como explicativas). A mesma metodologia foi utilizada nos modelos MQO estimados anteriormente, não havendo mudança qualitativa das conclusões.

No modelo SUR estimado, foram realizados testes simultâneos de Portmanteau para verificar a presença de autocorrelação residual. Ao nível de significância de 5\%, não

19 No caso, o Japão assume a primeira colocação, com a menor média de taxa de juros do período, e a Turquia aparece na posição 22 . 
se rejeitou a hipótese nula de ausência de autocorrelação até a defasagem 12. Testou-se, ainda, via teste de Breusch-Godfrey, a presença de autocorrelação de primeira ordem. Tal teste foi realizado equação por equação e também não se pôde rejeitar a nula de ausência de autocorrelação residual. Por fim, testes para heteroscedasticidade equação por equação também foram aplicados, e a hipótese nula de homoscedasticidade foi rejeitada para 7 dos 22 países a 5\% de significância. A nula, contudo, foi rejeitada a 1\% de significância apenas para um país.

De acordo com o capítulo 2, a literatura sobre modelos de precificação de ativos baseados em consumo é pautada por uma controvérsia empírica acerca da significância dos betas de consumo estimados. Lustig e Verdelhan (2007) encontram uma relação monotônica entre betas de consumo e média de taxa de juros, porém nenhum dos coeficientes estimados é significativo ao nível de 10\%. Ferreira e Moore (2015) encontram relevante ganho de eficiência dos coeficientes: no modelo com fatores de consumo domésticos e importados, 10 de 28 países (cerca de 36\%) possuem parâmetros conjuntamente significativos a um nível de $15 \%$.

Ao se comparar o modelo MQO estimado anteriormente no presente trabalho que utiliza a taxa de crescimento do PIB dos países como fatores de risco - com o modelo estimado em Ferreira e Moore (2015), não há alteração substancial na significância dos coeficientes estimados. O modelo condicional deste trabalho possui, também, cerca de $36 \%$ dos países com parâmetros conjuntamente significativos ao nível de $15 \%$.

A estimação SUR, no entanto, em comparação aos modelos até então presentes na literatura e aos modelos MQO da seção 4.1, provê, de fato, coeficientes $\beta_{1}^{j}$ e $\beta_{2}^{j}$ mais significativos, conforme se pode depreender da observação da tabela 4: há um aumento de mais de 50\% na significância conjunta dos betas, quando comparamos o SUR com o MQO condicional.

Por fim, seguindo a metodologia usada em Burnside (2011) e Ferreira e Moore (2015) foram realizados testes estatísticos com as seguintes hipóteses nulas: i) de que todos os betas estimados são iguais a zero; e ii) de que todos os betas são iguais a sua média (este denominado "teste de spreads"). Os resultados são revelados na tabela 5. 
Tabela 4: Percentagem de Betas Significantes

\begin{tabular}{lccr}
\hline & Nível de Confiança & MQO - 2 fatores & SUR \\
\hline$\beta_{2}^{j}$ & $15 \%$ & $22.73 \%$ & $27.27 \%$ \\
$\beta_{1}^{j}$ & $10 \%$ & $18.18 \%$ & $27.27 \%$ \\
\multirow{2}{*}{ Significância Conjunta } & $15 \%$ & $22.73 \%$ & $45.45 \%$ \\
& $10 \%$ & $18.18 \%$ & $40.91 \%$ \\
& $15 \%$ & $36.36 \%$ & $54.55 \%$ \\
\hline
\end{tabular}

Fonte: elaboração própria.

Tabela 5: Testes de Zeros e Spreads

\begin{tabular}{|c|c|}
\hline$\beta_{2}^{j}$ & $\beta_{1}^{j}$ \\
\hline \multicolumn{2}{|c|}{ Zeros (Estatística F) } \\
\hline $\begin{array}{c}3.0731 \\
* * *\end{array}$ & $\begin{array}{l}1.8180 \\
\quad * * *\end{array}$ \\
\hline \multicolumn{2}{|c|}{ Spreads (Estatística F) } \\
\hline $\begin{array}{c}3.4306 \\
* * *\end{array}$ & $\begin{array}{l}1.9003 \\
* * *\end{array}$ \\
\hline
\end{tabular}

Observa-se que, para ambos os testes realizados, as estatísticas F encontradas são elevadas. De fato, todas as estatísticas de teste são significativas a um baixo nível de significância: todos os p-valores são bem próximos de zero.

A partir dos resultados do modelo estimado via SUR, infere-se que não há relação relevante entre os coeficientes estimados $\hat{\beta}_{2}^{j}$ (referentes ao consumo de bens importados) e a média de taxa de juros dos diferentes países. Para os betas estimados $\hat{\beta}_{1}^{j}$ (associados ao fator de consumo de bens domésticos), por sua vez, tal relação se mostra presente, conclusão obtida pelos coeficientes estatisticamente significantes na regressão dos betas sobre média de juros e sobre a posição na classificação de média de taxas de juros.

Como teste de robustez do modelo apresentado, estima-se, ainda, um modelo SUR apenas para os países cujas taxas de juros Treasury Bills estavam disponíveis para a construção dos excessos de retorno. A ideia é verificar se os diferentes tipos de taxas de juros utilizadas influenciam, de alguma maneira, o resultado encontrado. O número de países da nova amostra se reduziu à metade: Brasil, Canadá, Hungria, Israel, Japão, 
México, Nova Zelândia, África do Sul, Suécia, Suíça e Reino Unido. O período amostral é, ainda, 1999T1 a 2014T2.

Pode-se dizer, a partir da observação da figura 12, que países com taxas de juros mais elevadas possuem maiores $\hat{\beta}_{1}^{j}$ estimados (ver, também, tabela 3 ). Não há padrão de comportamento específico em relação às médias de taxas de juros e os coeficientes $\hat{\beta}_{2}^{j}$.

No que diz respeito à significância dos parâmetros, estes são conjuntamente significantes a $10 \%$ para 5 países, o que representa $45,45 \%$ da nova amostra, resultado maior do que a chance. Ao se analisar os betas individualmente, $27,27 \%$ dos coeficientes $\hat{\beta}_{2}^{j}$ e $45,45 \%$ dos $\hat{\beta}_{1}^{j}$ são estatisticamente significativos, ambos a um nível de $10 \%$. Os testes de zeros e de spreads rejeitaram a hipótese nula a 1\% de significância. Os resultados encontrados, portanto, parecem robustos a mudanças nos instrumentos monetários utilizados.

Figura 12: Estimação SUR Treasury Bills: $\hat{\beta}_{1}^{j}$

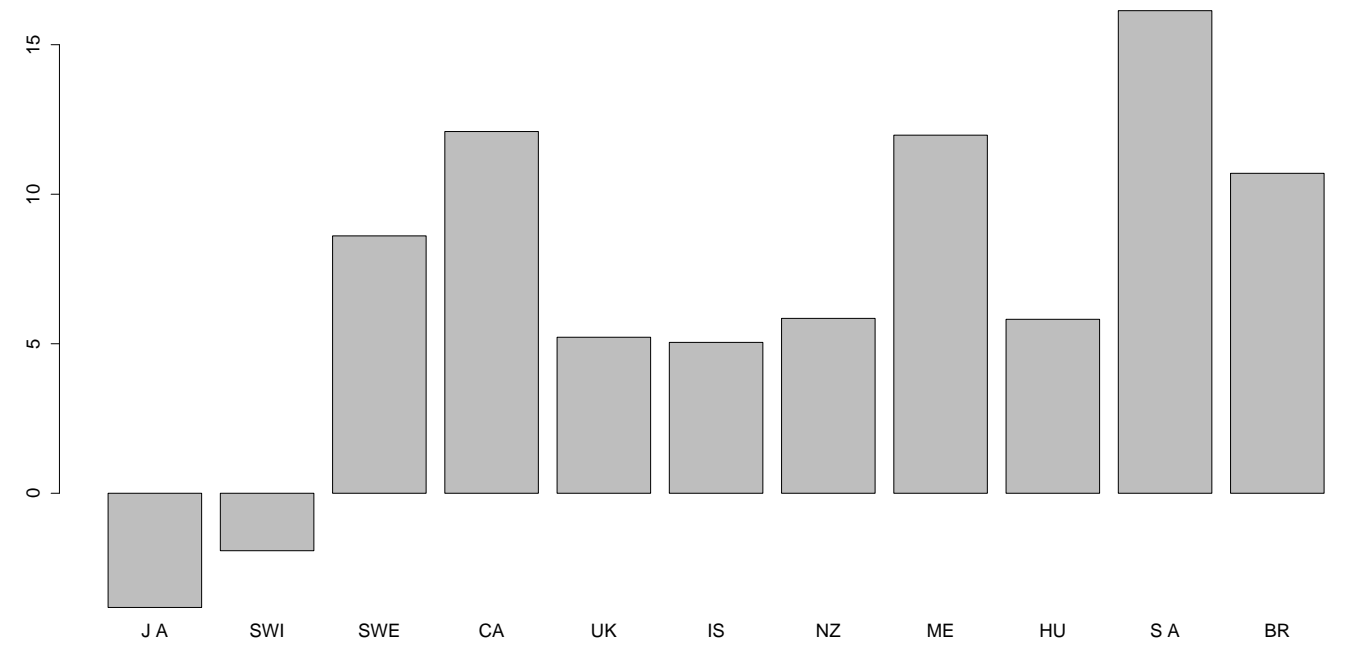

Fonte: elaboração própria.

\subsubsection{SUR Recursivo}

Ao longo do período amostral utilizado, o comportamento das taxas de juros dos países difere de maneira substancial. Bem como as taxas de juros, as taxas de câmbio também possuem comportamentos distintos ao longo do período analisado.

Diante de tais evidências, pode se esperar, também, que as quantidades de risco 
Figura 13: Estimação SUR Treasury Bills: $\hat{\beta}_{2}^{j}$

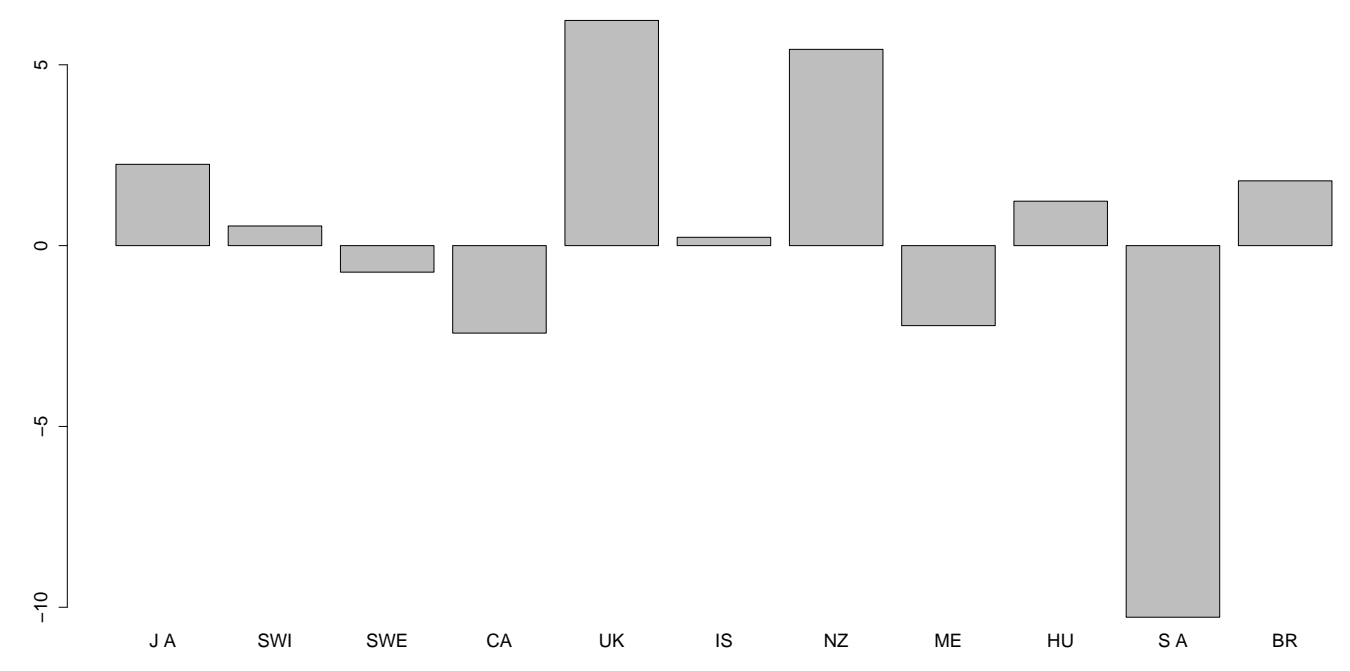

Fonte: elaboração própria.

estimadas para cada país difiram ao longo do tempo. Afinal, estas dependem da covariância entre consumo e excessos de retorno, os últimos obtidos a partir de dados de taxas de juros e de câmbio.

Com o objetivo de se verificar o comportamento da quantidade de risco estimada para cada país ao longo do tempo, estimou-se um modelo SUR recursivamente, ou seja, acrescentando-se um trimestre à amostra a cada estimação e guardando-se os betas obtidos. A primeira amostra utilizada contemplou o período de $1999 \mathrm{~T} 1$ a $2006 \mathrm{~T} 3^{20}$, a segunda contemplou o período de 1999T1 a 2006T4 e assim sucessivamente, até a amostra final 1999T1 a 2014T2. A ideia aqui é que cada observação adicionada à amostra anterior trará uma nova informação, impactando, portanto, a estimação das quantidades de risco.

A partir da estimação recursiva, têm-se séries dos coeficientes $\hat{\beta}_{1 t}^{j}$ e $\hat{\beta_{2 t}^{j}}$ para cada país j da amostra. Escolheu-se aqui mostrar os resultados para os seguintes países: $\beta_{1 t}^{\hat{K} O}$ para a Coréia do Sul (figura 14), $\beta_{1 t}^{\hat{T} U}$ para a Turquia (figura 15), $\beta_{1 t}^{\hat{I} S}$ para Israel (figura 16) e $\beta_{1 t}^{S W E}$ para a Suécia (figura 17). A escolha destas economias se deu a partir da análise das séries de betas estimados dos países da amostra: para os países escolhidos, mais de $60 \%$ dos betas da série são estatisticamente diferentes de zero. Em outras palavras,

$\overline{20}$ Escolheu-se dividir o período amostral pela metade para o início da estimação. 
pode-se dizer que as séries analisadas são estatisticamente diferentes de zero ${ }^{21}$.

Figura 14: Série da Quantidade de Risco $\beta_{1 t}^{\hat{K} O}$ - Coréia do Sul

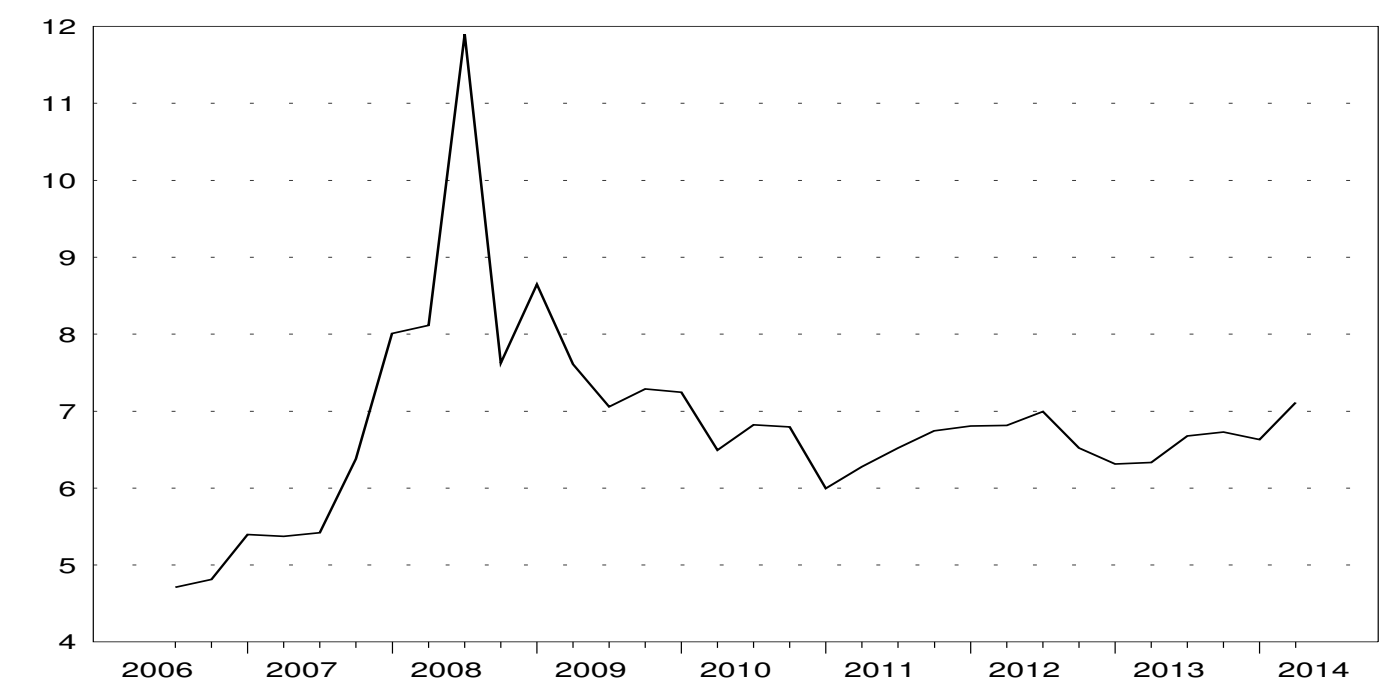

Fonte: elaboração própria.

Conforme se pode observar na figura 14, a quantidade de risco estimada por $\beta_{1 t}^{\hat{K} O}$ na economia da Coréia do Sul tem um pico quando o segundo trimestre de 2008 é incluído na amostra, retornando para patamares anteriores à crise lentamente a partir de então. Tal fato revela que, durante o auge da crise norte-americana, ou seja, quando o PIB e o consumo dos EUA diminuíram, $\beta_{1 t}^{\hat{K} O}$ aumentou, indicando que os excessos de retorno de títulos da Coréia caíram mais aceleradamente. Dessa forma, a moeda deste país mostrouse mais arriscada durante a crise de 2008 .

Também para a Turquia, observa-se comportamento semelhante, a partir da figura 15. Porém, com a inclusão dos trimestres de 2009 na amostra, a quantidade de risco estimada $\left(\beta_{1 t}^{\hat{T} U}\right)$ caiu para níveis inferiores aos níveis pré-crise. Em termos absolutos, a quantidade de risco da Turquia manteve-se acima à da Coréia do Sul.

Em relação a Israel, o comportamento dos coeficientes $\beta_{1 t}^{\hat{I} S}$ foi contrário ao encontrado nas economias indonésia e turca. Quando os trimestres de 2008 foram incluídos na amostra, a quantidade de risco estimada alcançou seu mínimo, próximo do valor de -4, indicando que, no início da crise norte-americana, os títulos israelitas se comportaram

21 Para as economias escolhidas, os parâmetros $\hat{\beta_{2 t}^{j}}$ não se mostram estatisticamente diferentes de zero para a maior parte das estimações realizadas para gerá-los, de modo que tais resultados não são apresentados. 
Figura 15: Série da Quantidade de Risco $\beta_{1 t}^{\hat{T} U}$ - Turquia

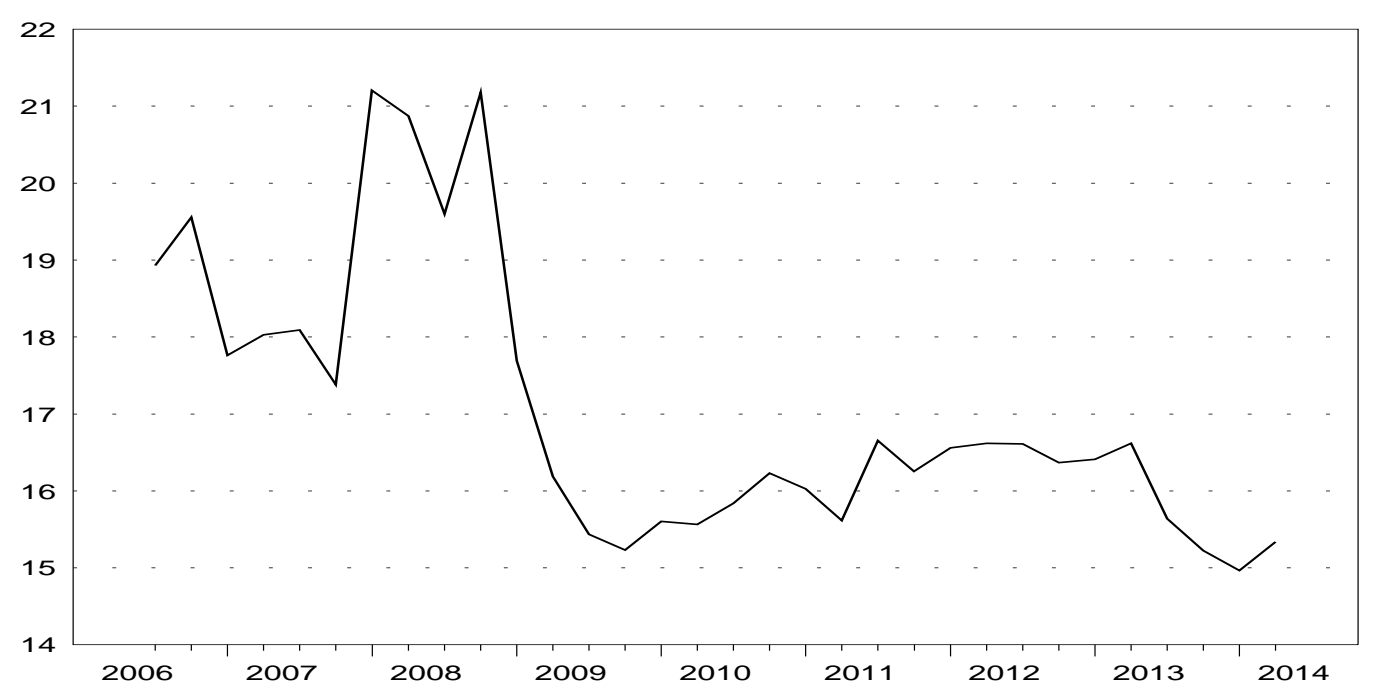

Fonte: elaboração própria.

Figura 16: Série da Quantidade de Risco $\beta_{1 t}^{\hat{I} S}$ - Israel

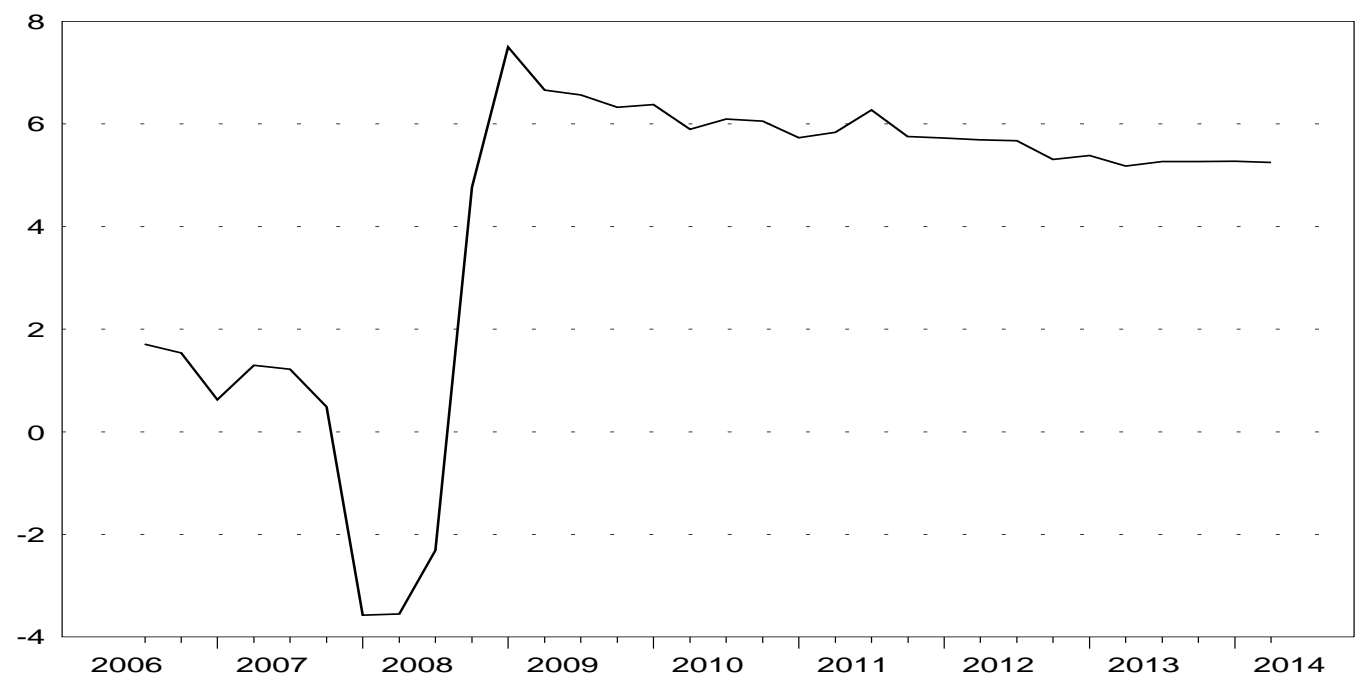

Fonte: elaboração própria. 
de maneira contra-cíclica, aumentando seu excesso de retorno. No entanto, a partir da inclusão do fim de 2008, os coeficientes $\beta_{1 t}^{\hat{I} S}$ aumentaram, voltando a valores positivos e superando o patamar pré-crise, o que pode refletir o contágio da crise sofrido pelo restante do mundo.

Para a Suécia, o comportamento da quantidade de risco estimada se assemelha ao observado para Israel: a inclusão dos trimestres de 2008 leva a série a alcançar o seu valor mínimo. Neste caso, porém, o valor mínimo continua positivo, o que significa que, embora a variação dos excessos de retorno tenha diminuído, estes ainda se comportam de maneira pró-cíclica com o PIB norte-americano . Com o contágio da crise no continente europeu, a quantidade de risco dada por $\beta_{1 t}^{S \hat{W E}}$ se eleva a patamares superiores ao nível pré-crise, retornando ao nível inicial a partir da inclusão dos trimestres de 2011.

Figura 17: Série da Quantidade de Risco $\beta_{1 t}^{S \hat{W E}}$ - Suécia

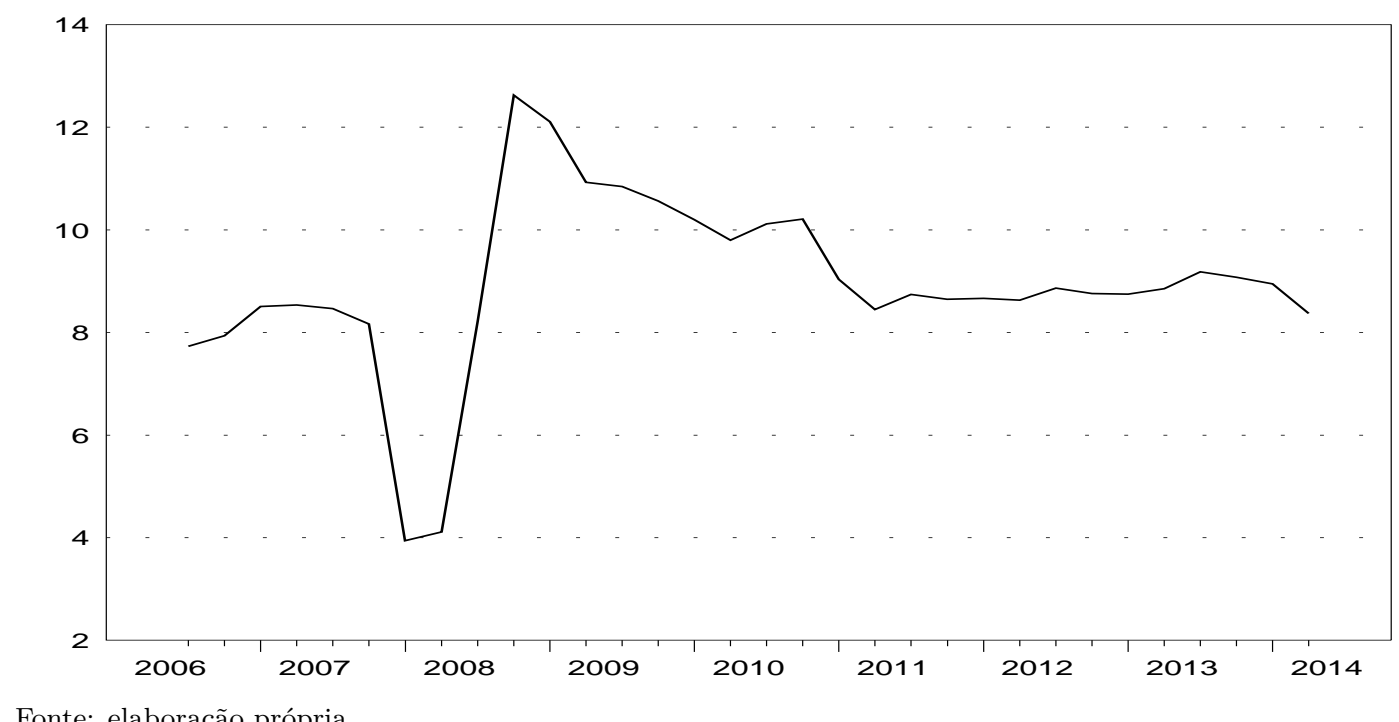

Fonte: elaboração própria.

Foram construídos gráficos semelhantes aos mostrados acima para todos os países da amostra. A análise país a país, porém, foge ao escopo deste trabalho, de modo que não foi aqui reportada. Além disso, nem todos os países apresentaram quantidades de risco estimadas estatisticamente significantes para a maior parte da amostra, de modo que a análise para esses casos foi considerada irrelevante.

Por fim, dada a não-linearidade das quantidades de risco ao longo do tempo, testouse uma especificação alternativa do modelo SUR apresentado na seção 4.2: incluiu-se, além 
dos fatores de risco $\left(\Delta y_{t}^{E U A}\right.$ e $\left.\Delta y_{t}^{j}\right)$, uma variável dummy que assume o valor 1 se o tempo t corresponde a uma recessão norte-americana e 0 caso contrário ${ }^{22}$. A ideia aqui é tentar captar os comportamentos diferentes do risco nos momentos de crise, como a que ocorreu em 2008. Os resultados do modelo alternativo não são aqui reportados pois a variável dummy incluída é significativa a um nível de $10 \%$ em apenas 3 das 22 equações. Dessa forma, mantém-se a especificação original do modelo descrita no capítulo 3.

\subsection{Classificações de Risco}

A média da taxa de juros é a métrica de classificação de risco utilizada na literatura (Ferreira e Moore (2015), Lustig e Verdelhan (2007), Burnside (2011), Lustig e Verdelhan (2011)), porém o risco pode ser classificado de outras maneiras. O próprio excesso de retorno, por exemplo, engloba o risco dos títulos das diferentes moedas. As depreciações médias da taxa de câmbio em momentos de recessão, além disso, também podem ser vistas como uma métrica de risco. A ideia aqui é que, em momentos de recessão nos Estados Unidos, os países que tiverem as maiores depreciações são aqueles cujos títulos pagarão menos relativamente a títulos norte-americanos. Dessa forma, as quantidades de risco estimadas para esses países seriam positivas e elevadas.

Tendo em vista tais considerações, apresenta-se na presente seção como as quantidades de risco estimadas pelo modelo SUR se comportam de acordo com i) a distribuição dos excessos de retorno médio entre os países e ii) a distribuição das depreciações médias durante recessões dos Estados Unidos.

As figuras 18 e 19 apresentam os betas classificados em ordem crescente do excesso de retorno médio de cada um dos países da amostra.

Similarmente ao que acontecia quando se ordenava os betas estimados de acordo com a taxa de juros média, os coeficientes $\hat{\beta}_{2}^{j}$ não possuem um comportamento específico em relação aos excessos de retorno médio dos países. Para os parâmetros $\hat{\beta}_{1}^{j}$, as menores quantidades de risco estimadas se concentram na distribuição inferior dos excessos de retorno, mas não se consegue inferir visualmente um padrão para os maiores coeficientes $\overline{22}$ A variável dummy é definida a partir do indicador de recessões norte-americanas do NBER. 
Figura 18: Estimação SUR: $\hat{\beta}_{1}^{j}$ ordenados por excesso de retorno médio

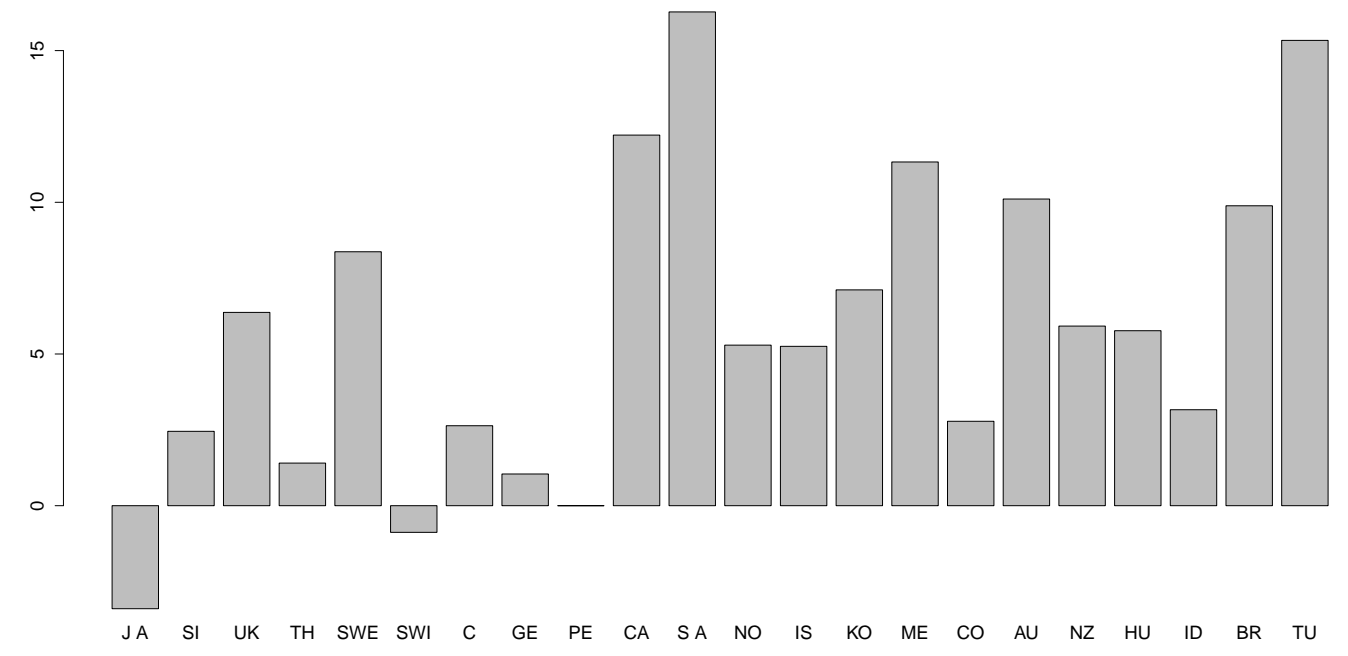

Fonte: elaboração própria.

Figura 19: Estimação SUR: $\hat{\beta}_{2}^{j}$ ordenados por excesso de retorno médio

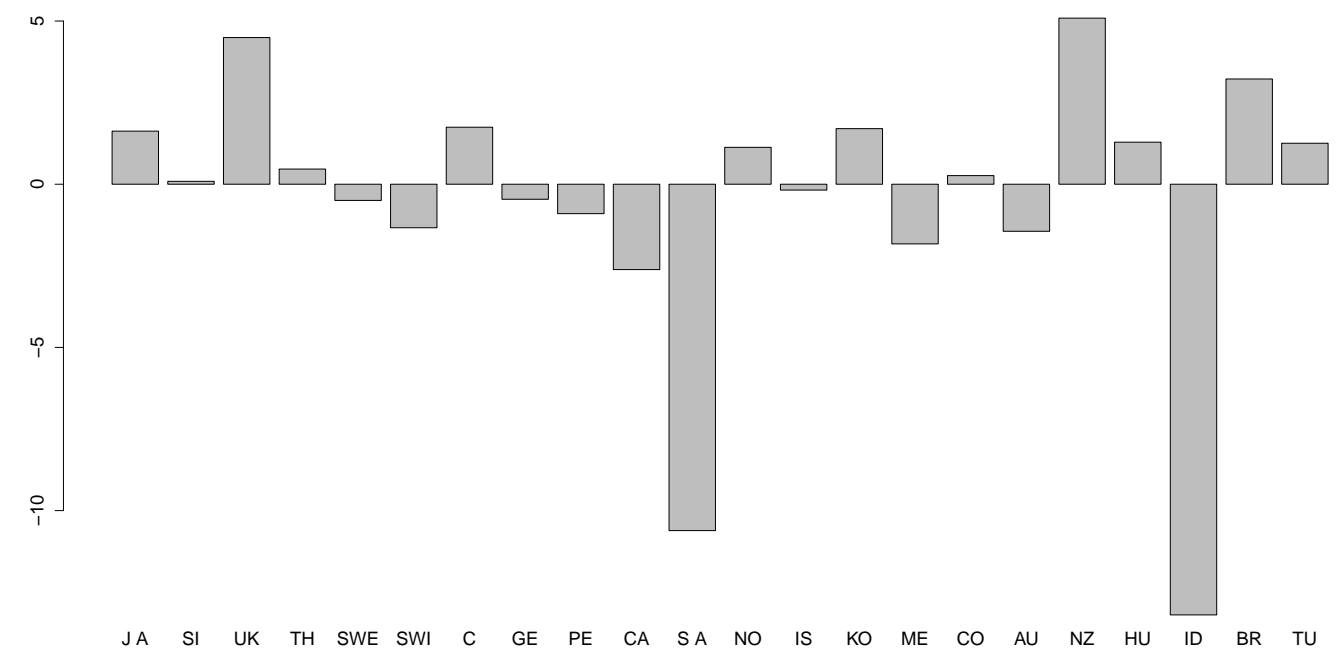

Fonte: elaboração própria. 
estimados. A partir da tabela 6, depreende-se que, de fato, a quantidade de risco representada pelo parâmetro $\hat{\beta}_{1}^{j}$ possui relação positiva e estatisticamente significativa com os excessos de retorno médios de cada país: para o aumento de 1 ponto percentual no excesso de retorno médio, a quantidade de risco estimada aumenta em 0,92899. A relação positiva e significativa também é encontrada com os betas estimados por MQO.

Apresenta-se, também, os betas estimados pelo modelo SUR classificados em ordem crescente da depreciação média das taxas de câmbio de cada país no momento de recessões norte-americanas ${ }^{23}$. As figuras 20 e 21 mostram essa relação:

Figura 20: Estimação SUR: $\hat{\beta}_{1}^{j}$ ordenados por depreciação média

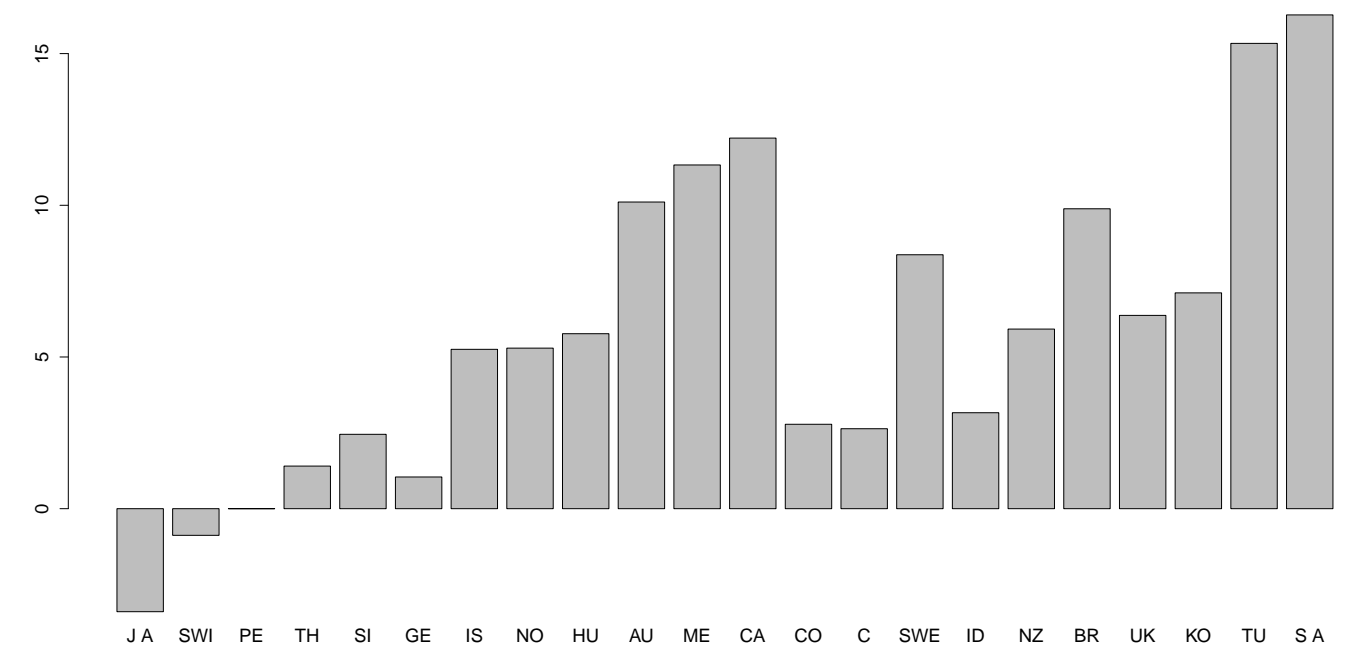

Fonte: elaboração própria.

Novamente, os coeficientes $\hat{\beta}_{2}^{j}$ não possuem um comportamento específico em relação à depreciação média dos países. Pode-se inferir visualmente, contudo, uma relação positiva entre os parâmetros $\hat{\beta}_{1}^{j}$ e a média das depreciações dos países em momentos de recessão norte-americana. De fato, a partir da tabela 6, vê-se que essa relação é estatisticamente significativa e positiva. Para os modelos estimados por MQO, a significância estatística se mantém.

$\overline{23}$ Os períodos de recessões dos Estados Unidos foram definidos de acordo com o indicador de recessão do NBER. 
Figura 21: Estimação SUR: $\hat{\beta}_{2}^{j}$ ordenados por depreciação média

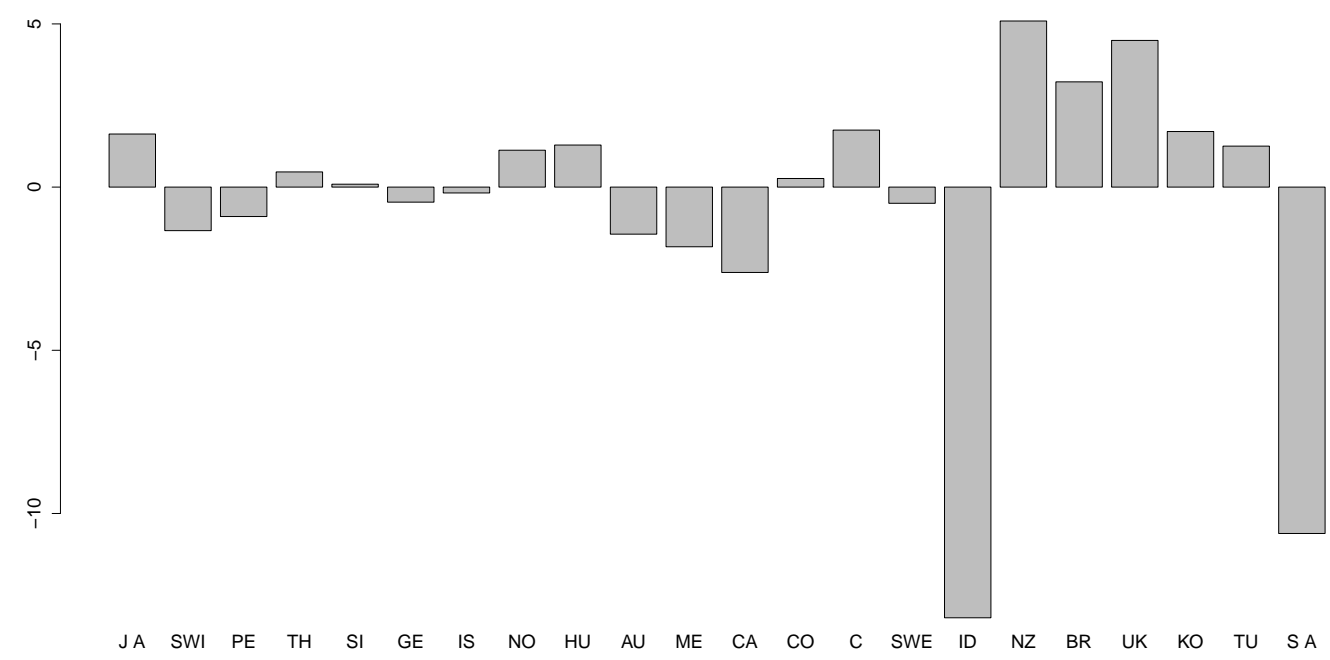

Fonte: elaboração própria.

Tabela 6: Regressão dos Betas sobre Excesso de Retorno Médio e Depreciação Média

\begin{tabular}{|c|c|c|c|c|}
\hline Variáveis Explicativas & \multicolumn{4}{|c|}{ Variável Dependente } \\
\hline SUR & \multicolumn{2}{|c|}{$\hat{\beta_{2}^{j}}$} & \multicolumn{2}{|c|}{$\hat{\beta_{1}^{j}}$} \\
\hline Constante & -0.4703 & 0.6849 & $2.2853^{*}$ & 0.8727 \\
\hline Excesso de Retorno Médio & -0.0040 & - & $0.9289 * * *$ & - \\
\hline Depreciação Média na Recessão & - & -1.2694 & - & $5.3834 * * *$ \\
\hline MQO - 2 fatores & \multicolumn{2}{|c|}{$\hat{\beta_{2}^{j}}$} & \multicolumn{2}{|c|}{$\hat{\beta}_{1}^{j}$} \\
\hline Constante & 0.3034 & 1.6162 & 1.3358 & -0.1552 \\
\hline Excesso de Retorno Médio & 0.0791 & - & $0.8782 * *$ & - \\
\hline Depreciação Média na Recessão & - & -1.0951 & - & $5.2580 * * *$ \\
\hline MQO - 1 fator & \multicolumn{2}{|c|}{$\hat{\beta_{2}^{j}}$} & \multicolumn{2}{|c|}{$\hat{\beta_{1}^{j}}$} \\
\hline Constante & 1.4268 & 1.2724 & 1.3843 & 0.5243 \\
\hline Excesso de Retorno Médio & 0.1339 & - & $0.9704 * * *$ & - \\
\hline Depreciação Média na Recessão & - & 0.7226 & - & $4.9561^{* * *}$ \\
\hline
\end{tabular}

Fonte: elaboração própria. Nota: *** denota significância a 1\%, ** significância a 5\%, ${ }^{*}$ significância a $10 \%$. 


\subsection{Outros testes de robustez}

Conforme já mencionado, todos os modelos estimados no presente estudo seguem o ponto de vista de um agente norte-americano. Em outras palavras, trabalhou-se aqui com excessos de retorno de títulos estrangeiros em relação aos títulos dos EUA, cuja moeda é a mais negociada no mercado mundial.

Outros países, contudo, também possuem moedas com grande participação no mercado de câmbio internacional. Buscando testar se as evidências obtidas pelos modelos associados aos EUA também são válidas para outros países, apresenta-se, a seguir, resultados de modelos estimados do ponto de vista de agentes de outras nacionalidades: i) agentes alemães (sendo estes uma proxy para os agentes europeus, dado que a Alemanha é a única representante da Zona do Euro em nossa amostra) - e ii) agentes britânicos. As equações a serem estimadas via SUR para os respectivos modelos são, portanto:

$$
\begin{array}{ll}
R_{t}^{j, G E}=\beta_{0}^{j, G E}+\beta_{1}^{j, G E} \Delta y_{t}^{G E}+\beta_{2}^{j, G E} \Delta y_{t}^{j}+u_{t}^{j, G E} & j=1,2, \ldots, J \\
R_{t}^{j, U K}=\beta_{0}^{j, U K}+\beta_{1}^{j, U K} \Delta y_{t}^{U K}+\beta_{2}^{j, U K} \Delta y_{t}^{j}+u_{t}^{j, U K} & j=1,2, \ldots, J
\end{array}
$$

Construiu-se, dessa maneira, as séries de excessos de retorno de títulos estrangeiros

em relação aos títulos alemães $R_{t}^{j, G E}$ e as séries de retornos em excesso em relação aos títulos britânicos $R_{t}^{j, U K}$. A metodologia para a construção dessas séries foi a mesma definida na seção 3.2.1 do capítulo 3, utilizada para os excessos de retorno de títulos norteamericanos: primeiramente, obteve-se as séries mensais para sua posterior transformação em séries trimestrais. Para tanto, foram necessários os dados mensais de inflação de Grã-Bretanha e Alemanha, bem como suas taxas de juros mensais. Esses dados estavam disponíveis na base IFS do FMI.

No que diz respeito às taxas de câmbio em relação ao euro e à libra (moeda do país j/euro e moeda do país j/libra), a maior parte delas foi obtida junto aos sites do Banco Central Europeu (European Central Bank) e do Banco Central Inglês (Bank of England), 
respectivamente. Quando não havia disponibilidade de dados, as taxas de câmbio foram construídas via paridade cruzada: multiplicou-se a taxa dólar/euro pelas respectivas taxas moeda do país j/dólar para se obter a taxa moeda do país j/euro; o mesmo raciocínio foi utilizado para se obter as taxas moeda do país j/libra dos países para os quais os dados não estavam disponíveis.

Para o euro, taxas de câmbio via paridade cruzada foram construídas para quatro países: Chile, Colômbia, Israel e Peru. Os dados também não estavam disponíveis para o Brasil antes do ano 2000, de modo que se completou a série com a multiplicação de paridades para o ano de 1999. As primeiras observações de todas as séries trimestrais de excessos de retorno para os títulos alemães foram construídas com base apenas na média dos excessos de retorno dos meses de Fevereiro e Março de 1999: a variação cambial entre Janeiro de 1999 e Dezembro de 1998 se refere à última cotação do marco e à primeira do euro, não sendo, portanto, válida. Para evitar a contaminação dos dados, excluiu-se a primeira observação de todas as séries mensais construídas.

Em relação à libra, utilizou-se paridades cruzadas para a construção da totalidade das séries de taxa de câmbio mensais para os seguintes países: Brasil, Chile, Colômbia, Indonésia, México e Peru. Para outros países, foi necessário completar a série disponível até determinado período da amostra: Hungria, Israel, Coréia, Singapura, Tailândia e Turquia $^{24}$. Para o restante dos países, toda a série de taxa de câmbio estava disponível no site do Banco Inglês.

Os resultados dos modelos estimados são reportados nas figuras 22 e 23, para Alemanha e Reino Unido, respectivamente. Nessas figuras, tem-se os coeficientes $\beta_{1}^{j, G E}$ e $\beta_{1}^{j, U K}$ estimados ordenados por média de taxa de juros. Apresenta-se aqui apenas as quantidades de risco associadas ao PIB doméstico, uma vez que, para os coeficientes $\beta_{2}^{j, U K}$ e $\beta_{2}^{j . G E}$, não se observa padrão específico de comportamento em relação à média de taxa de juros, similarmente ao que ocorria para o modelo do ponto de vista de um agente norte-americano.

24 Hungria: até Set/03; Israel, Coréia e Turquia: até Mar/05; Singapura: até Dez/99; Tailândia: até Abr/05. 
Figura 22: Estimação SUR: $\hat{\beta_{1}^{j, G E}}$

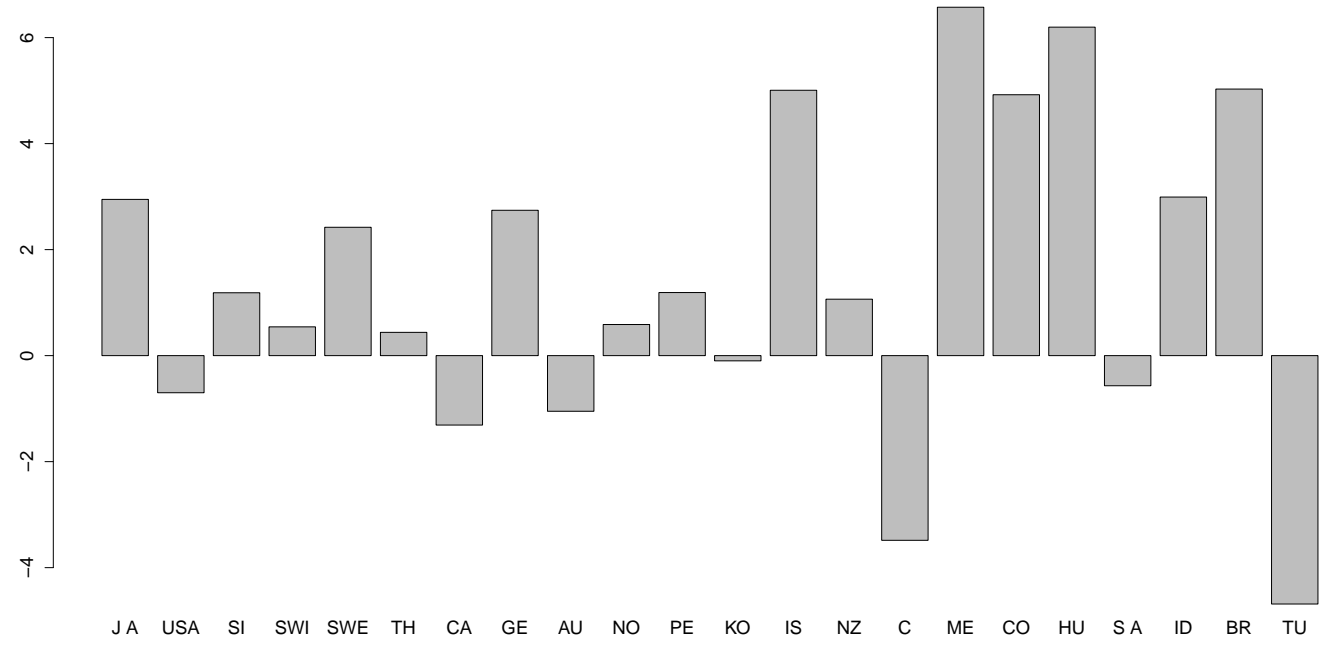

Fonte: elaboração própria.

Figura 23: Estimação SUR: $\beta_{1}^{j, \hat{U} K}$

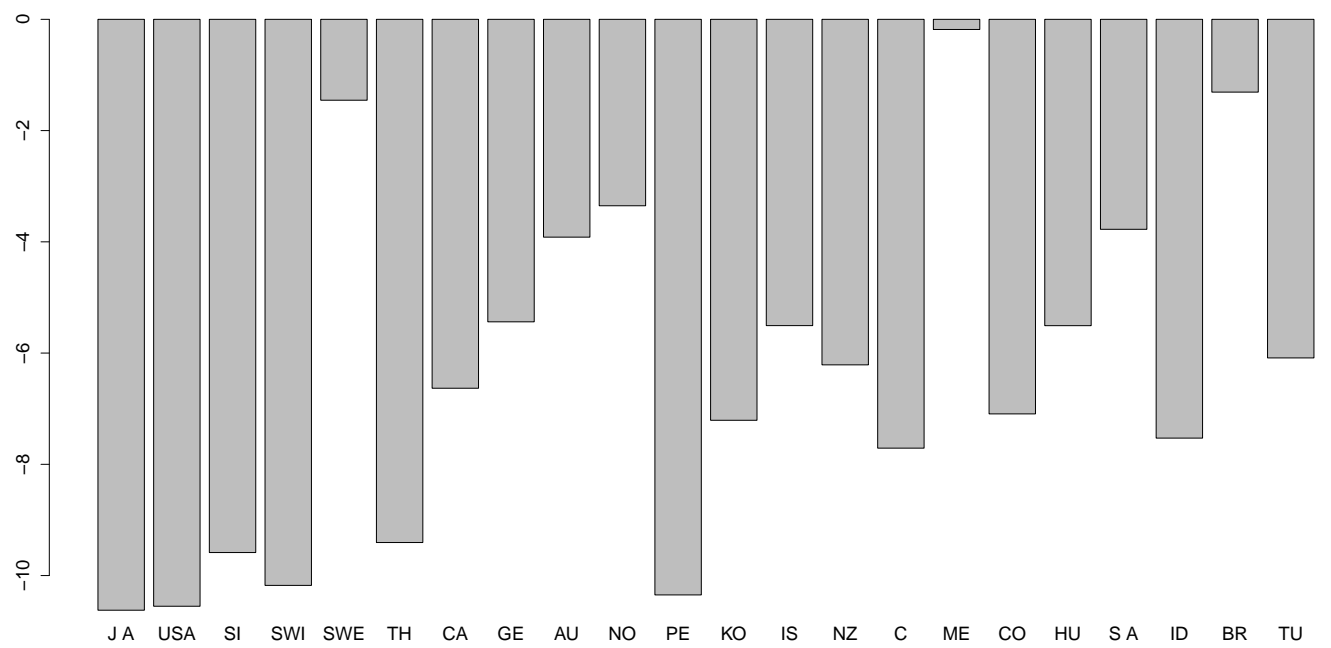

Fonte: elaboração própria. 
No modelo para a Alemanha, contudo, também não se infere nenhum tipo de comportamento para os parâmetros $\beta_{1}^{j, G E}$ : não parece haver relação entre as quantidades de risco estimadas e as taxas de juros médias dos j países da amostra. Em uma regressão dos coeficientes estimados $\beta_{1}^{j, G E}$ e $\beta_{2}^{j, G E}$ sobre uma constante e as médias das taxas de juros, os p-valores dos coeficientes de inclinação estimados são 0,5993 e 0,4826, respectivamente. Logo, no modelo estimado para a Alemanha, não há evidência estatística de que maiores quantidades de risco estariam associadas a maiores taxas de juros médias.

No que diz respeito ao modelo do ponto de vista de um agente britânico, há uma diferença interessante em relação aos modelos estimados anteriormente: conforme se depreende da figura 23, os coeficientes $\beta_{1}^{j, U K}$ estimados são negativos para todos os países da amostra. Tal resultado, à primeira vista contra-intuitivo, é explicado a partir da correlação negativa entre as séries de excesso de retorno e a taxa de crescimento do PIB britânico. Isso significa que os excessos de retorno de títulos estrangeiros em relação aos títulos britânicos respondem de maneira contra-cíclica a pioras na economia: quando a economia do Reino Unido desacelera e os níveis de consumo diminuem, os títulos estrangeiros tendem a aumentar seu excesso de retorno em relação aos títulos domésticos britânicos. Japão e Estados Unidos possuem os maiores betas, em módulo, sendo considerados menos arriscados para um agente inglês. A quantidade de risco estimada para o Brasil, por sua vez, é uma das menores em módulo: o excesso de retorno de títulos brasileiros em relação a títulos britânicos aumenta durante a recessão inglesa, mas aumenta menos que o excesso de retorno de títulos japoneses e norte-americanos. É interessante observar que, embora o sinal dos betas estimados seja negativo nesse modelo, a relação de monotonicidade entre quantidades de risco e média de taxa de juros pode ser observada.

Os resultados desses modelos estimados via MQO não são reportados pois os betas obtidos por esse método são qualitativamente iguais aos betas estimados via SUR: não há evidência estatística de correlação positiva entre quantidade de risco e média de juros em nenhum dos modelos estimados para a Alemanha; enquanto para o Reino Unido, apenas os coeficientes $\beta_{1}^{j, U K}$ estimados possuem relação significativa com as médias de taxas de 
$\operatorname{juros}^{25}$.

Em relação à significância estatística dos parâmetros, contudo, a estimação via SUR se mostra, novamente, mais eficiente que as estimações MQO, conforme se depreende dsa tabelas 7 e 8 . Mesmo quando a porcentagem de betas significativos na amostra é pequena, a estimação de um modelo SUR provê uma maior quantidade de coeficientes significativos a $10 \%$ e a $15 \%$ quando comparada a uma estimação MQO com os dois fatores de risco no modelo.

Tabela 7: Percentagem de Betas Significantes: Modelo Alemanha

\begin{tabular}{lccc}
\hline & Nível de Confiança & MQO - 2 fatores & SUR \\
\hline$\beta_{2}^{j}$ & $15 \%$ & $22.73 \%$ & $45.45 \%$ \\
\multirow{2}{*}{$\beta_{1}^{j}$} & $10 \%$ & $18.18 \%$ & $45.45 \%$ \\
\multirow{2}{*}{ Significância Conjunta } & $15 \%$ & $13.64 \%$ & $18.18 \%$ \\
& $10 \%$ & $4.55 \%$ & $9.09 \%$ \\
& $15 \%$ & $36.36 \%$ & $50.00 \%$ \\
\hline
\end{tabular}

Fonte: elaboração própria.

Tabela 8: Percentagem de Betas Significantes: Modelo Reino Unido

\begin{tabular}{lccr}
\hline & Nível de Confiança & MQO - 2 fatores & SUR \\
\hline$\beta_{2}^{j}$ & $15 \%$ & $18.18 \%$ & $45.45 \%$ \\
& $10 \%$ & $18.18 \%$ & $40.91 \%$ \\
$\beta_{1}^{j}$ & $15 \%$ & $54.55 \%$ & $54.55 \%$ \\
\multirow{2}{*}{ Significância Conjunta } & $10 \%$ & $36.36 \%$ & $50.00 \%$ \\
& $15 \%$ & $45.45 \%$ & $59.09 \%$ \\
& $10 \%$ & $45.45 \%$ & $54.55 \%$ \\
\hline
\end{tabular}

Fonte: elaboração própria.

Em relação aos testes de spreads e de zeros, rejeitou-se, a um nível de $5 \%$ de significância, as hipóteses nulas i) de que todos os betas estimados são iguais a sua média (teste de spreads; e ii) de que todos os betas são iguais a zero (teste de zeros). As estatísticas de teste são apresentadas nas tabelas 10 e 12 nos anexos.

Testou-se, também, a presença de autocorrelação nos resíduos: para os dois modelos, o teste de Breusch-Godfrey realizado equação por equação não rejeitou a nula de

$\overline{25} \quad$ Nos anexos, reporta-se as tabelas 9 e 11 , que trazem os resultados de regressões dos betas estimados sobre médias de taxas de juros. 
ausência de autocorrelação de primeira ordem para nenhum dos países da amostra. O teste de Breusch-Pagan para heteroscedasticidade também foi aplicado a cada equação, rejeitando a nula de homoscedasticidade a 1\% de significância para a maioria dos países da amostra.

A partir da estimação via SUR de modelos para a Alemanha e para o Reino Unido, têm se que, como esperado, a estimação via SUR melhora, de fato, a precisão dos coeficientes estimados quando comparada à estimação MQO. A relação monotônica entre quantidades de risco estimadas e médias de taxas de juros, entretanto, é corroborada apenas pelo modelo do ponto de vista de um britânico, não havendo evidências estatísticas no modelo para a Alemanha.

\section{Considerações Finais}

Este estudo se insere na fronteira da literatura de precificação de ativos, na medida em que complementa o trabalho de Ferreira e Moore (2015), que é baseado em fatores de consumo domésticos e importados, mais condizentes com um problema de uma economia aberta. A maior contribuição do presente trabalho está em se utilizar o crescimento do PIB das economias como fatores de risco no lugar dos fatores de consumo, a partir de uma hipótese de equilíbrio geral. A escolha do PIB como fator de risco garante a consistência entre a teoria e a implementação empírica, permitindo a estimação do modelo linear via SUR - Seemingly Unrelated Regressions. Dessa maneira, ao invés de estimações MQO equação por equação, explora-se a correlação estrutural entre os choques das diferentes equações do sistema de precificação de ativos.

A estratégia empírica utilizada traz maior eficiência aos parâmetros do modelo, melhorando a sua precisão. Os resultados da estimação SUR revelam que, de fato, a percentagem de coeficientes conjuntamente significativos quase dobra ao se comparar com as estimações MQO realizadas em Ferreira e Moore (2015). Tais evidências são reportadas tanto no modelo de excessos de retorno em relação a títulos norte-americanos, como nos

modelos do ponto de vista de agentes alemães e europeus. É importante ressaltar que a 
escolha do crescimento do PIB dos países como fatores de risco também contribui para a maior precisão dos coeficientes, uma vez que o produto possui maiores variações no tempo do que o consumo, sendo assim um fator de risco mais compatível com a alta volatilidade dos excessos de retorno.

No que diz respeito à relação positiva entre quantidades de risco estimadas e médias de taxas de juros, esta é observada nos modelos do ponto de vista de um agente norteamericano e de um agente britânico, mas não há evidências estatísticas no modelo para a Alemanha. Além disso, a significância estatística dessa relação ocorre apenas para os coeficientes associados ao consumo de bens domésticos.

Este estudo também inova ao apresentar uma estimação recursiva que analisa o comportamento da quantidade de risco dos diferentes países ao longo do tempo. Os resultados corroboram a teoria ao atestarem que os países que se revelam mais arriscados são aqueles que, em momentos de recessão norte-americana, apresentam picos em sua série de betas. Ou seja, países cujos excessos de retorno respondem mais negativamente à queda do consumo nesse período.

Por fim, uma contribuição marginal do presente trabalho é levantar a discussão acerca de classificações de risco alternativas. As quantidades de risco parecem estar relacionadas positivamente não somente com a média de taxa de juros, mas também com a depreciação média na recessão e com o excesso de retorno médio dos países. Tais relações só são estatisticamente significativas para os coeficientes associados ao consumo de bens domésticos. 



\section{Referências}

BIS. Triennial Central Bank Survey, Foreign exchange turnover in April 2013: preliminary global results. [S.l.], 2013.

BURNSIDE, C. The cross section of foreign currency risk premia and consumption growth risk: Comment. American Economic Review, v. 101, n. 7, p. 3456-76, 2011.

COCHRANE, J. H. Asset pricing. [S.l.]: Princeton university press Princeton, 2005.

EPSTEIN, L. G.; ZIN, S. E. Substitution, risk aversion, and the temporal behavior of consumption and asset returns: A theoretical framework. Econometrica: Journal of the Econometric Society, p. 937-969, 1989.

FAMA, E. F.; MACBETH, J. D. Risk, return, and equilibrium: Empirical tests. The Journal of Political Economy, p. 607-636, 1973.

FERREIRA, A. Teoria econômica e evidências empíricas do risco cambial. Tese (Doutorado) - Tese de Livre Docência). Universidade de São Paulo, Faculdade de Economia, Administração e Contabilidade de Ribeirão Preto (USP/FEA-RP), Ribeirão Preto-SP., 2014.

FERREIRA, A. L.; MOORE, M. J. Carry trade e risco cambial: um conto de dois fatores. Revista Brasileira de Economia, SciELO Brasil, v. 69, n. 4, p. 429-449, 2015.

GREENE, W. H. Econometric analysis. [S.l.]: Pearson Education India, 2003.

HAYASHI, F. Econometrics. 2000. Princeton University Press. Section, 2000.

LUCAS, R. J. Interest rates and currency prices in a two-country world. Journal of Monetary Economics, Elsevier, v. 10, n. 3, p. 335-359, 1982.

LUSTIG, H.; VERDELHAN, A. The cross section of foreign currency risk premia and consumption growth risk. American Economic Review, v. 97, n. 1, p. 89-117, 2007.

LUSTIG, H.; VERDELHAN, A. The cross-section of foreign currency risk premia and consumption growth risk: Reply. American Economic Review, v. 101, n. 7, p. 3477-3500, 2011.

ROMER, D. Advanced Macroeconomics. 4th edition. ed. [S.l.]: McGraw-Hill Irwin, 2010.

YOGO, M. A consumption-based explanation of expected stock returns. The Journal of Finance, Wiley Online Library, v. 61, n. 2, p. 539-580, 2006.

ZELLNER, A. An efficient method of estimating seemingly unrelated regressions and tests for aggregation bias. Journal of the American statistical Association, Taylor \& Francis, v. 57, n. 298, p. 348-368, 1962. 


\section{ANEXO}

Tabela 9: Regressão dos Betas sobre Médias de Taxa de Juros e Posições no Rank: Modelo Alemanha

\begin{tabular}{lcccc}
\hline Variáveis Explicativas & \multicolumn{4}{c}{ Variável Dependente } \\
\hline SUR & \multicolumn{2}{c}{$\beta_{2}^{\hat{j, G E}}$} & \multicolumn{3}{c}{$\beta_{1}^{\hat{j, G E}}$} \\
Constante & 0.56740 & 1.71448 & $1.87227^{*}$ & 0.73194 \\
Média Tx. Juros & -0.06969 & - & -0.06931 & - \\
Posição no Rank & - & -0.13650 & - & 0.06261 \\
\hline MQO - 2 fatores & \multicolumn{2}{c}{$\beta_{2}^{\hat{j, G E}}$} & \multicolumn{2}{c}{$\beta_{1}^{j, G E}$} \\
Constante & 2.11363 & 2.91679 & 1.09561 & -0.00980 \\
Média Tx. Juros & -0.15104 & - & 0.01025 & - \\
Posição no Rank & - & -0.14949 & - & 0.10153 \\
\hline MQO - 1 fator & \multicolumn{2}{c}{$\beta_{2}^{j, G E}$} & \multicolumn{2}{c}{$\beta_{1}^{j, G E}$} \\
Constante & $1.74680 * *$ & 0.81568 & $2.17788^{*}$ & 2.81821 \\
Média Tx. Juros & -0.02868 & - & -0.13828 & - \\
Posição no Rank & - & 0.06584 & - & -0.12861 \\
\hline
\end{tabular}

Fonte: elaboração própria. Nota: ${ }^{* * *}$ denota significância a $1 \%,{ }^{* *}$ significância a $5 \%,{ }^{*}$ significância a $10 \%$.

Tabela 10: Testes de Zeros e Spreads: Modelo Alemanha

\begin{tabular}{|c|c|}
\hline$\beta_{2}^{j, G E}$ & $\beta_{1}^{j, G E}$ \\
\hline \multicolumn{2}{|c|}{ Zeros (estatística F) } \\
\hline 4.72009 & 2.73191 \\
\hline$* * *$ & $* * *$ \\
\hline \multicolumn{2}{|c|}{ Spreads (estatística F) } \\
\hline 4.77407 & 2.60871 \\
\hline$* * *$ & $* * *$ \\
\hline
\end{tabular}


Tabela 11: Regressão dos Betas sobre Médias de Taxa de Juros e Posições no Rank: Modelo Reino Unido

\begin{tabular}{|c|c|c|c|c|}
\hline Variáveis Explicativas & \multicolumn{4}{|c|}{ Variável Dependente } \\
\hline SUR & \multicolumn{2}{|c|}{$\beta_{2}^{j, \hat{U} K}$} & \multicolumn{2}{|c|}{$\beta_{1}^{j, \hat{U} K}$} \\
\hline Constante & -0.44158 & 0.13755 & $-7.23509 * * *$ & $-8.95585 * * *$ \\
\hline Média Tx. Juros & -0.00126 & - & 0.14621 & - \\
\hline Posição no Rank & - & -0.05103 & - & $0.22698 * *$ \\
\hline MQO - 2 fatores & \multicolumn{2}{|c|}{$\beta_{2}^{j, \hat{U} K}$} & \multicolumn{2}{|c|}{$\beta_{1}^{j, \hat{U} K}$} \\
\hline Constante & -0.28050 & -0.47014 & $-7.44812 * * *$ & $-8.60831 * * *$ \\
\hline Média Tx. Juros & -0.02847 & - & $0.19989 * *$ & - \\
\hline Posição no Rank & - & 0.00143 & - & $0.20663 *$ \\
\hline MQO - 1 fator & \multicolumn{2}{|c|}{$\beta_{2}^{j, \hat{U} K}$} & \multicolumn{2}{|c|}{$\beta_{1}^{j, \hat{U} K}$} \\
\hline Constante & $-2.78632 * *$ & $-3.95458 *$ & $-7.54700 * * *$ & $-9.59056 * * *$ \\
\hline Média Tx. Juros & 0.08795 & - & $0.22923 * *$ & - \\
\hline Posição no Rank & - & 0.14811 & - & $0.29896 *$ \\
\hline
\end{tabular}

Fonte: elaboração própria. Nota: ${ }^{* * *}$ denota significância a $1 \%,{ }^{*}$ significância a $5 \%,{ }^{*}$ significância a $10 \%$.

Tabela 12: Testes de Zeros e Spreads: Modelo Reino Unido

\begin{tabular}{cc}
\hline$\beta_{2}^{j, U K}$ & \multicolumn{1}{c}{$\beta_{1}^{j, U K}$} \\
\hline Zeros & (estatística $\mathbf{F})$ \\
3.61376 & 1.81968 \\
$* * *$ & $* *$ \\
Spreads & (estatística $\mathbf{F})$ \\
3.75170 & 1.64668 \\
$* * *$ & $* *$ \\
\multicolumn{2}{l}{$\begin{array}{l}\text { Fonte: elaboração própria. Nota: } \\
\text { denota significância a 1\%, }\end{array}$} \\
cia a significân- \\
5\%, * significância a 10\%.
\end{tabular}

